\title{
Effects of Hearing Preservation on Psychophysical Responses to Cochlear Implant Stimulation
}

\author{
Stephen Y. Kang, ${ }^{1}$ Deborah J. Colesa, ${ }^{1}$ Donald L. Swiderski, ${ }^{1}$ Gina L. Su, ${ }^{1}$ Yehoash Raphael, ${ }^{1}$ \\ AND BRYAN E. Pfingst ${ }^{1}$ \\ ${ }^{1}$ Kresge Hearing Research Institute, Department of Otolaryngology, University of Michigan, Ann Arbor, MI 48109-5616, USA
}

Received: 14 August 2008; Accepted: 1 October 2009; Online publication: 10 November 2009

\begin{abstract}
Previous studies have shown that residual acoustic hearing supplements cochlear implant function to improve speech recognition in noise as well as perception of music. The current study had two primary objectives. First, we sought to determine how cochlear implantation and electrical stimulation over a time period of 14 to 21 months influence cochlear structures such as hair cells and spiral ganglion neurons. Second, we sought to investigate whether the structures that provide acoustic hearing also affect the perception of electrical stimulation. We compared psychophysical responses to cochlear implant stimulation in two groups of adult guinea pigs. Group I (11 animals) received a cochlear implant in a previously untreated ear, while group II (ten animals) received a cochlear implant in an ear that had been previously infused with neomycin to destroy hearing. Psychophysical thresholds were measured in response to pulse-train and sinusoidal stimuli. Histological analysis of all group I animals and a subset of group II animals was performed. Nine of the 11 group I animals showed survival of the organ of Corti and spiral ganglion neurons adjacent to the electrode array. All group I animals showed survival of these elements in regions apical to the electrode array. Group II animals that were examined histologically showed complete loss of the organ of Corti in regions adjacent and apical to the electrode array and severe spiral ganglion neuron loss, consistent with previous reports for neomycin-treated ears. Behaviorally,
\end{abstract}

Correspondence to: Bryan E. Pfingst - Kresge Hearing Research Institute, Department of Otolaryngology - University of Michigan · Ann Arbor, MI 48109-5616, USA. Telephone: +1-734-7632292; fax: +1-734-7640014; email: bpfingst@umich.edu group II animals had significantly lower thresholds than group I animals in response to $100 \mathrm{~Hz}$ sinusoidal stimuli. However, group I animals had significantly lower thresholds than group II animals in response to pulse-train stimuli (0.02 ms/phase; 156 to 5,000 pps). Additionally, the two groups showed distinct threshold versus pulse rate functions. We hypothesize that the differences in detection thresholds between groups are caused by the electrical activation of the hair cells in group I animals and/or differences between groups in the condition of the spiral ganglion neurons.

Keywords: electrical stimulation, residual hearing, auditory prosthesis, guinea pig, neomycin, hair cells, spiral ganglion

\section{INTRODUCTION}

Criteria for cochlear implantation have changed since the devices were first introduced. Early in the history of cochlear implantation, candidacy was mostly limited to those patients with profound bilateral sensorineural deafness. However, implantation guidelines have expanded to include an increasing number of patients with greater residual acoustic hearing, and efforts have been made to preserve that hearing during the implantation surgery (Gstoettner et al. 2006). Moreover, in recent years, combined electrical and acoustic stimulation in ears with residual hearing has been introduced (von Ilberg et al. 1999; Gantz and Turner 2003; Kiefer et al. 2005; Turner et al. 2008).

Acoustic stimulation has been shown to provide spectral and temporal fine-structure information that supplements electrical hearing and can improve 
speech recognition in noise as well as music perception in cochlear implant users (Turner et al. 2008). However, it is probable that surviving hair cells and related cochlear elements also directly affect electrical hearing. Cochlear implant function in hearing versus deaf ears has been studied in some detail at the neurophysiological level (Moxon 1971; van den Honert and Stypulkowski 1984; Shepherd and Javel 1997; Miller et al. 2006), but we know less about the effects of preserved acoustic hearing on the responses to electrical stimulation at the psychophysical perceptual level. Thus, studies exploring the effects of preserving acoustic hearing on the perception of cochlear implant electrical stimulation are needed.

Cochlear implants bypass missing or damaged hair cells by electrically stimulating surviving neurons in the auditory nerve. In the deaf cochlea, cochlear implants likely stimulate the spiral ganglion cell bodies or fibers distal or proximal to them (Wilson and Dorman 2008). Although hair cells and peripheral processes are not required for cochlear implant function, if these structures are present in an electrically stimulated cochlea, it is possible that they impact the perception of an electrical stimulus. There are several possible mechanisms by which this might occur. Electrical stimulation can result in basilar membrane motion by several mechanisms, including electrically induced contraction of outer hair cells (OHCs), resulting in mechanical stimulation of inner hair cells (IHCs) and electrophonic hearing (Stevens and Jones 1939; Moxon 1971; van den Honert and Stypulkowski 1984; McAnally et al. 1993; Nuttall and Ren 1995; Le Prell et al. 2006; Miller et al. 2006). It is also possible that the radial component of the electrical current results in direct excitation of the peripheral process and/or the IHC (van den Honert and Stypulkowski 1984). Furthermore, IHCs might generate spontaneous activity in the auditory nerve, which, by desynchronizing the population of auditory nerve fibers, may affect the across-fiber synchrony or the size of the neural population activated by the electrical stimulation (Wilson 1997; Haenggeli et al. 1998; Hu et al. 2003). The presence of hair cells might also have an indirect effect by supporting the survival of neural elements that affect electrical hearing, such as spiral ganglion neurons (SGNs; Spoendlin 1984; Green et al. 2008).

If increased survival of hair cells and SGNs provide benefit to electrical hearing, it is important to elucidate the effects that cochlear implantation and electrical stimulation may have on these elements. One animal study suggests that cochlear implantation surgery causes hearing loss due to the direct acute trauma of electrode insertion combined with subsequent apoptotic cell death of hair cells (Eshraghi et al. 2005). The effects of electrical stimulation on hair cells have also been studied in the past in several animal species, with mixed results that depend partly on charge density (Walsh et al. 1981; Duckert and Miller 1982; Duckert 1983; Ni et al. 1992; Xu et al. 1997; Coco et al. 2007). Thus, cochlear pathology may be a result of the implantation surgery or the electrical stimulation itself. Regardless of the mechanism of injury, with the growing number of patients receiving cochlear implants with residual acoustic hearing, it is important to determine the timeline of survival of hair cells and related cochlear elements following cochlear implantation and electrical stimulation.

There were two objectives of this study. First, we sought to evaluate the survival and preservation of hair cells, SGNs, and acoustic hearing in guinea pigs following cochlear implantation and periodic electrical stimulation over a period of up to 21 months. Second, we investigated the effects of the preservation of acoustic hearing on the perception of the electrical stimulus. Specifically, we studied differences in the psychophysical detection of electrical sinusoids and pulse trains in (a) animals that had normal hearing prior to cochlear implantation and (b) animals that received neomycin infusion into the cochlea prior to implantation with the intent of destroying acoustic hearing.

\section{METHODS}

\section{Research design}

To determine the effects of hearing preservation on psychophysical responses to cochlear implant stimulation, two groups of guinea pigs were studied. Group I consisted of 11 guinea pigs that received a cochlear implant in a normal ear. Group II consisted of ten animals that received a cochlear implant in an ear that was treated with a cochlear perfusion of neomycin. Previous studies have shown that intracochlear neomycin treatment led to degeneration of hair cells and a transformation of the non-sensory cells in the organ of Corti resulting in a simple ("flat") epithelium (Duckert 1983; Davies et al. 1994; Kim and Raphael 2007). Additionally, previous studies have found that intracochlear neomycin treatments result in the loss of all responses to acoustic stimulation within approximately 10 min (Nuttall et al. 1977; Middlebrooks and Snyder 2007). Ototoxically treated guinea pigs typically show a significant loss of SGNs at 2 weeks posttreatment and a much greater loss by 2-4 months (Webster and Webster 1981). In the basal turn of the cochlea, Webster and Webster (1981) found that approximately $73 \%$ of SGNs remained 2 weeks posttreatment, $15 \%$ remained $2-4$ months post-treatment, and $11 \%$ remained $8-15$ months post-treatment. As psychophysical thresholds in our neomycin-treated 
animals were collected at least 3 months posttreatment, large differences in hearing and cochlear morphology were expected between group I and group II animals.

A summary of the study design is shown in Figure 1, which describes the order of onset of psychophysical testing. All animals underwent acoustic psychophysical training and then were placed in either group I or group II. Group I animals received intracochlear neomycin in the cochlea that was contralateral to the ear that would later receive a cochlear implant. The purpose of infusing neomycin into the ear contralateral to the implant was to ensure that the acoustic thresholds obtained following implantation in these animals were due to the detection of acoustic stimuli in the ear that received the cochlear implant. The non-treated ear underwent daily acoustic testing for approximately 3 months until thresholds stabilized. In this study, acoustic thresholds were considered stable if there were no upward or downward trends with five consecutive thresholds within a standard deviation less than $10 \mathrm{~dB}$ at three frequencies: 8 , 16 , and $24 \mathrm{kHz}$. Following threshold stabilization, animals received a cochlear implant in the non-treated
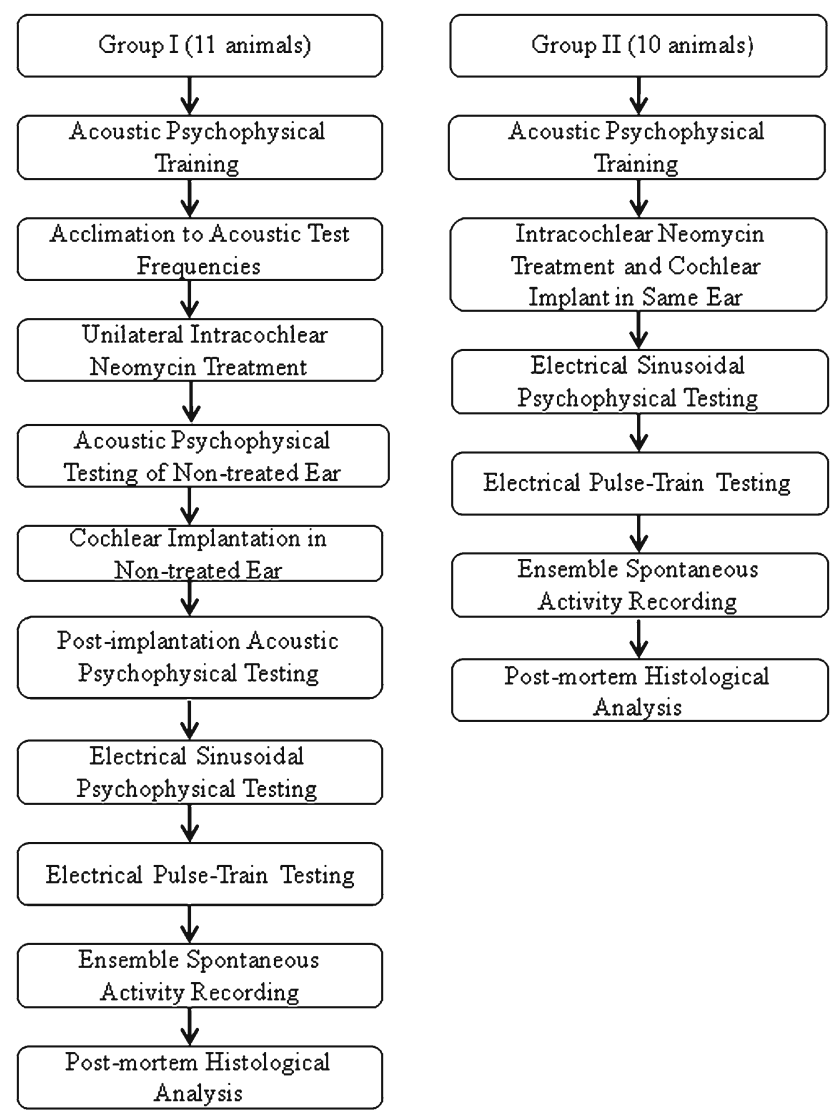

FIG. 1. Flow chart summarizing the experimental paradigm. The sequence boxes represent the order of onset of the testing, although psychophysical testing of electrical sinusoids, pulse trains, and acoustic stimuli occurred throughout the study. ear. Following implantation, acoustic thresholds were measured for approximately 1-2 months until they stabilized using the same criterion described above. Once post-implantation acoustic thresholds stabilized, electrical testing began, and acoustic thresholds were measured on a weekly basis, interleaved with electrical threshold testing throughout the remainder of the post-implantation period.

Group II animals underwent intracochlear neomycin treatment and cochlear implantation in the same ear. Thus, they did not undergo acoustic testing following implantation but instead immediately began electrical testing. Four group II animals received bilateral neomycin injections, while six group II animals received neomycin only in the implanted ear.

Psychophysical electrical-detection thresholds using sinusoidal stimuli $(100 \mathrm{~Hz})$ were measured in both groups of animals. The $100-\mathrm{Hz}$ sinusoidal stimulus was chosen to monitor changes in thresholds following the onset of electrical stimulation because previous studies have shown it to be more sensitive to changes in threshold over time compared to shorter phase-duration pulses (Pfingst 1990). Decreases in thresholds to $100 \mathrm{~Hz}$ electrical sinusoids often occur during the first month after implantation followed by a long period of threshold stability (Miller et al. 2000; Su et al. 2008). Although analog stimuli are not used as commonly as pulsatile stimuli in most current speech processing strategies, they have been used successfully (Stollwerck et al. 2001; Zwolan et al. 2001; $\mathrm{Xu}$ et al. 2005) and can convey information not present in pulse trains. In analog processors, stimulus frequencies as low as $100 \mathrm{~Hz}$ can be useful for representing voice fundamental frequency. Thresholds for the electrical sinusoids were determined using a monopolar electrode configuration at two different intracochlear locations. The delivered stimulus during electrical psychophysical threshold testing was purely electrical; there was no acoustic component to the delivered stimulus.

Once thresholds for the sinusoidal stimuli became stable, testing with pulse trains $(0.02 \mathrm{~ms} /$ phase $)$ at pulse rates of $156,313,625,1,250,2,500$, and 5,000 pulses per second (pps) began, and additional thresholds for the $100-\mathrm{Hz}$ sinusoids were measured periodically. Pulse trains were chosen because they serve as the carrier signal for spatial and temporal-envelope encoding in the majority of current cochlear implants. Pulse rate affects the neural representation of the carrier (Middlebrooks 2004), and it affects perception of the low-frequency-modulated envelope of the pulse train carrier that represents much of the important information conveyed by cochlear prosthesis processing and stimulation strategies (Galvin III and Fu 2005; Pfingst et al. 2007). Importantly, the neural representation of the pulse-train carriers at 
various pulse rates probably depends on the condition of the stimulated neural population. Middlebrooks (2004) reported that interaction of pulses in neomycin-treated guinea pigs occurred at pulse rates above 1,000 pps. Based on those data, we chose pulse rates bracketing 1,000 pps and covering rates commonly used in current cochlear prostheses. We tested the hypothesis that integration of pulse trains at various pulse rates and the resulting detection thresholds would be affected by the preservation or degeneration of hair cells and SGNs. Similar to the procedure for the sinusoidal stimulus, thresholds for pulse trains were determined using monopolar electrode configurations at two different intracochlear locations, and there was no acoustic component to the delivered stimulus.

In the absence of hair cells, the auditory nerve is normally silent, but when hair cells are present, there is spontaneous activity, which can affect the responses of the nerve to electrical stimulation (Wilson 1997; Haenggeli et al. 1998; Hu et al. 2003; Miller et al. 2006). In our study, the presence or absence of spontaneous activity in the auditory nerve was assessed by recording ensemble activity (Dolan et al. 1990; Searchfield et al. 2004) from the cochlear implant electrodes in all group I animals and in four group II animals.

After completion of all psychophysical and electrophysiological testing, histological analysis was performed in all group I animals and three group II animals to evaluate the status of the ears, with particular focus on the hair cell and SGN populations.

Figure 1 reports the order in which the various tests and treatments took place. However, in order to report data that were obtained from the same time period, psychophysical thresholds in response to acoustic (in group I animals) and electrical sinusoids were obtained on a weekly basis following initiation of the pulse-train stimulus. By the end of the experiment, group I animals were undergoing psychophysical testing in response to acoustic, electrical sinusoidal, and electrical pulse-train stimuli interleaved over the same time period. Similarly, group II animals were undergoing psychophysical testing in response to electrical sinusoid and pulse-train stimuli. The thresholds reported in this manuscript were from the time period following initiation and stabilization of the electrical pulse trains, when animals were undergoing psychophysical testing in response to multiple types of stimuli.

In group I animals, electrical thresholds were obtained over a total implantation time of 14 to 21 months. Psychophysical testing was conducted 5 days a week for approximately 2 to $3 \mathrm{~h}$ per day. However, since the stimulation was not continuous, the total duration of electrical stimulation was limited to a small fraction of the time that was spent in the testing booth. As a result, the subjects in this study received much less electrical stimulation as compared to other studies that employed chronic electrical stimulation to test safe limits or protective effects of electrical stimulation (Walsh et al. 1981; Duckert and Miller 1982; Duckert 1983; Ni et al. 1992; Xu et al. 1997; Coco et al. 2007).

\section{Subjects}

Subjects tested in this experiment were adult male, pigmented, specific pathogen-free guinea pigs. At the time of their arrival from the Elm Hill breeding facility (Chelmsford, MA, USA), animals weighed approximately $160 \mathrm{~g}$. They were gradually acclimated to a sound-attenuating chamber and a restraint harness that kept them oriented toward the front of the test chamber. Their diet remained unrestricted until they weighed approximately $400 \mathrm{~g}$. In addition to the food pellets (Noyes/Research Diets) received in the testing chamber during psychophysical testing, the animals received $25 \mathrm{~g}$ of food pellets per day after each testing session, ensuring that the animals were motivated to perform the positively reinforced task while maintaining a healthy weight. Weights stabilized around 800 to $1,200 \mathrm{~g}$. Animals were always allowed free access to water. This study was performed in accordance with National Institutes of Health Guidelines (Guide for the Care and Use of Laboratory Animals, 1996). The University Committee on the Use and Care of Animals at the University of Michigan approved the animal protocols. Veterinary care and animal husbandry were provided by the Unit for Laboratory Animal Medicine in facilities certified by the Association for Assessment and Accreditation of Laboratory Animal Care, International.

\section{Cochlear implants}

Animals received an eight-electrode scala tympani implant, manufactured by Cochlear Corporation (Nucleus, Ltd., Lane Cove, Australia). However, only five or six of the electrodes could be safely inserted into the scala tympani as detailed below. The diameter of the implant was $0.41 \mathrm{~mm}$, and the centers of the electrodes were $0.75 \mathrm{~mm}$ apart. The electrodes were given letter designations. The most apical electrode in the array was designated $\mathrm{A}$, the second $\mathrm{B}$, third $\mathrm{C}$, and so on. Electrical stimulation was delivered at one apical electrode and one basal electrode. Note that "apical" and "basal" refer to the relative position of the electrodes in the array. All of the electrodes were implanted in the basal turn of the scala tympani. The electrodes chosen for electrical testing were B for the more apical electrode and $\mathrm{D}$ or $\mathrm{E}$ for the more basal 
electrode, depending on the depth of insertion. If six electrodes were inserted, E was chosen as the basal electrode, and if five electrodes were inserted, D was the basal electrode. In animal 345, electrode B malfunctioned and electrode A was used for the apical electrode. The apical stimulation site, or electrode B in most animals, will be referred to as stimulation site 1. The basal stimulation site, the $\mathrm{D}$ or E electrode, will be referred to as stimulation site 2 .

\section{Surgical procedures}

Both the intracochlear neomycin treatment and the implantation procedures were performed under anesthesia using sterile surgical procedures. The same surgical protocol was followed for both groups of animals. Ketamine (40 $\mathrm{mg} / \mathrm{kg}$ ) and xylazine (10 mg/kg) were used for anesthesia, and a single dose of atropine $(0.05 \mathrm{mg} / \mathrm{kg})$ was given to decrease mucosal secretions while anesthetized. For the intracochlear neomycin treatment procedure, $60 \mu \mathrm{l}$ of a $10 \%(w / v)$ neomycin sulfate solution in sterile water was injected through the round window. The neomycin was gradually injected over a time course of approximately $1 \mathrm{~min}$. Perilymph and perfusate drained from the round window during the injection. The volume of neomycin injected through the round window was purposely in excess of the volume of the scala tympani to facilitate neomycin diffusion throughout the cochlea.

The cochlear implantation procedure began by exposing the skull via a midline incision on the head. Three screws were placed in the skull in a triangle around bregma. These screws held the head of a screw used to secure the implant connector and used as a ground for ensemble spontaneous activity (ESA) recordings and psychophysical testing if the internal ground electrode became broken. A percutaneous connector was then mounted on the skull with methyl methacrylate. Next, a postauricular incision was made and the bulla was exposed. Using the tip of a scalpel blade, a small hole in the bulla was made. A cochleostomy was made in the base of the cochlea near the round window with a diamond bur. The electrode array and cable were led under the postauricular muscle into the opening made in the bulla, and the electrode array was inserted into the scala tympani through the cochleostomy.

The diameter of the implant $(0.41 \mathrm{~mm})$ was such that it met resistance when it was inserted approximately $4.5 \mathrm{~mm}$ from the cochleostomy due to the narrowing of the scala tympani. Previous dissections of similarly implanted cochleae revealed that the apical electrodes lay in close proximity to the modiolus while the basal electrodes varied in their distances from the modiolus, with the medial edge of the basal electrode ranging from 0 to $0.7 \mathrm{~mm}$ away from the modiolus (Pfingst and Colesa 2003).

Implant insertion depths were estimated at the time of implantation based on the number of electrode rings observed outside the cochleostomy. Insertion depths ranged from 3.8 to $4.6 \mathrm{~mm}$. No electrode was implanted to a depth beyond the basal turn of the scala tympani. Once the implant reached the maximum depth allowed by the dimensions of the scala tympani, the cable was secured at the bulla defect with a silk tie and Durelon cement. The ground electrode was tucked into the muscle overlying the temporal bone, and the incision was closed.

\section{Equipment and test environment}

For the psychophysical tasks, subjects were tested in custom-built wire-mesh test cages located inside sound-attenuating chambers produced by Acoustic Systems (Model RF Shielded Animal Test Chambers), Industrial Acoustics Corporation (Model 1201-A), or Tracoustics (Models 240-B and 240-C). Stimulus generation and delivery for psychophysical testing were controlled by a locally written program running on personal computers. Stimuli were processed by Tucker Davis Technologies digital to analog converters (DA3-2) and attenuated by Tucker Davis Technologies programmable attenuators (PA4). Acoustic signals were amplified (Parasounds Zap/Zone, HCA500 , HCA- 600 or HCA-750A) and presented by speakers mounted above the test cages. Electrical stimuli were delivered by a custom-built voltage controlled constant current stimulator.

The sound levels of the 8-, 16-, and 24-kHz tones were measured with a Brüel and Kjær type $41361 / 4^{\prime \prime}$ condenser microphone fixed near the ear of a simulated guinea pig made of felt and plastic that was located in the test cage approximately where the guinea pigs would stand during the psychophysical testing. The microphone output was buffered by a Brüel and Kjær type 2619 preamplifier and connected to the input of a Stanford Research type SR760 fast Fourier transform (FFT) analyzer. The root mean square (RMS) average of the microphone signal was acquired during tone presentation and converted to sound pressure level (SPL). Approximately every 6 months, SPLs for all tones were measured and compared to desired levels and to previous calibrations. If outputs had varied from the desired level, tone levels were restored to desired levels by increasing or decreasing the output of the power amplifier. SPLs for all the rooms and tones varied an average standard deviation of $4.0 \mathrm{~dB}$ SPL with a minimum and maximum of 1.7 and $7.9 \mathrm{~dB}$ SPL, respectively. To convert thresholds to $\mathrm{dB}$ SPL, the attenuation at threshold ( $\mathrm{dB}$ below 0 attenuation) was subtracted 
from the average SPL at $0 \mathrm{~dB}$ attenuation for each tone.

\section{Psychophysical training}

A positive reinforcement paradigm was used to train the animals to respond to acoustic and electrical stimuli. Subjects were trained to perform a psychophysical task in which they initiated a trial by pressing a button (the observing response) and reported detection of an acoustic signal by releasing the button. The training signal was a $1-\mathrm{kHz}$ tone presented in $200 \mathrm{~ms}$ bursts separated by $100 \mathrm{~ms}$ intervals. Animals learned to press and hold down the button through a randomly variable period, ranging from 1 to $6 \mathrm{~s}$ prior to the stimulus onset, and then to release it within $1 \mathrm{~s}$ of the auditory stimulus onset. Button releases within $1 \mathrm{~s}$ of stimulus onset were rewarded by delivery of a food pellet. Once the animals responded reliably at a level of $55 \mathrm{~dB}$ SPL, they were trained to respond to lower levels of sound intensity. Stimulus tables consisted of six to eight levels of attenuation at a step size of $5 \mathrm{~dB}$ for acoustic stimuli and $2 \mathrm{~dB}$ for electrical stimuli. These stimuli were presented in random order. Stimulus levels were selected to maintain a relatively constant rate of positive reinforcement across conditions in order to avoid situations that might lead to a change in response strategy. Levels were adjusted such that approximately four of the levels were suprathreshold and two were subthreshold. The percentage of correct responses as a function of attenuation level was assessed, and the detection threshold was defined as the level at which the animal responded correctly $50 \%$ of the time, as determined by linear interpolation from the psychometric function. Guess rates (releases of the response button during a 1-s unmarked observation period on "catch" trials where no stimulus was presented) were measured during all sessions. Of the total number of trials, $11 \%$ to $14 \%$ were "catch" trials. Thresholds were considered valid if subjects completed at least 15 trials at each stimulus level, generated a smooth psychometric function, and had a guess rate that was no greater than $20 \%$.

\section{Electrical stimulation parameters}

When electrical testing was initiated in both groups, electrical thresholds were tested for $100 \mathrm{~Hz}$ sinusoidal electrical stimuli presented in $200 \mathrm{~ms}$ bursts separated by $100 \mathrm{~ms}$ intervals. Upon initiation of this testing, current levels were at subthreshold level (approximately $-70 \mathrm{~dB}$ re $1 \mathrm{~mA}$ RMS) and were gradually raised until detectable levels were reached. Initial levels were carefully chosen based on initial psychophysical thresholds of previously tested animals, which usually ranged from -40 to $-60 \mathrm{~dB}$ re $1 \mathrm{~mA}$ RMS. Animals were carefully observed during the initial period of stimulation to monitor the head and pinna for involuntary movement during delivery of the electrical stimulus to avoid situations of overstimulation.

Monopolar stimulation was used, and thresholds were obtained for stimulation at site 1 and site 2 . Electrical thresholds for $100 \mathrm{~Hz}$ sinusoids were obtained until they stabilized. The criterion for stability was ten consecutive electrical thresholds with a standard deviation $\leq 2.0 \mathrm{~dB}$ and a slope not significantly different from zero $(p>0.05)$ as determined by linear regression. The slope criterion for sinusoidal stimuli was used because thresholds typically decrease in the first few weeks following implantation (Miller et al. 2000; Su et al. 2008). After psychophysical thresholds for the $100-\mathrm{Hz}$ sinusoidal electrical stimuli became stable, psychophysical testing in response to pulse-train stimuli began.

Psychophysical thresholds were obtained using electrical pulse trains at pulse rates of $156,313,625$, $1,250,2,500$, and 5,000 pps in all animals with the exception of two group II animals that did not undergo testing at 5,000 pps. The stimuli were $0.02 \mathrm{~ms} /$ phase biphasic pulses with a negative leading phase in $200 \mathrm{~ms}$ bursts separated by $100 \mathrm{~ms}$ intervals. Electrical thresholds were obtained with monopolar stimulation at site 1 and site 2 in all animals with the exception of one group II animal that only underwent testing at site 1 . The stabilization criterion for pulsetrain stimuli was five consecutive thresholds with a standard deviation $\leq 2.0 \mathrm{~dB}$. By the time the animals were tested with pulse-train stimuli, the observed thresholds were much more stable over time so the slope criterion used for sinusoids was not necessary.

\section{Measurement of spontaneous activity}

ESA of the auditory nerve (Dolan et al. 1990; Searchfield et al. 2004) was recorded from the site 1 electrode. The recorded electrical potential was filtered from $300 \mathrm{~Hz}$ to $3.0 \mathrm{kHz}$, amplified with a gain of 10,000 , and transmitted to a spectrum analyzer (SR760, Stanford Research Systems, Sunnyvale, CA, USA). The SR760 had a sampling rate of $256 \mathrm{kHz}$. The frequency span of the SR760 was set from zero to $12.5 \mathrm{kHz}$, which resulted in analysis of $32 \mathrm{~ms}$ timedomain records. An FFT was performed on each record, using Blackman-Harris windowing. The frequency resolution of the resulting FFT (which depended on the span setting of the SR760) was $31.25 \mathrm{~Hz}$. One hundred fifty FFTs were acquired and averaged (linear, RMS averaging). A MATLAB ${ }^{\text {TM }}$ script, written in-house, was used to retrieve the waveform from the SR760 and store the data. For each animal tested, the response level $(\mathrm{dBv})$ and 
frequency at which the maximum activity occurred within the frequency range of 422 to $1,203 \mathrm{~Hz}$ was extracted (Table 2). This window, centered at $900 \mathrm{~Hz}$, was based on the bandwidth of the spectrum analyzer for the chosen sampling rate.

\section{Impedance measurements}

Impedances were measured using a custom-built impedance meter with a $1-\mathrm{kHz}$ sinusoidal test current at $1 \mu \mathrm{A}$ RMS. The impedances of all electrodes were measured on a weekly basis following psychophysical testing. These impedances were used to monitor the electrical integrity of the implant. Electrodes with impedance values that were greater than $2 \mathrm{M} \Omega$ were unmeasurable by the impedance meter, and these electrodes were considered to be nonfunctional.

\section{Perfusion and histological processing}

Following completion of psychophysical and electrophysiological data collection, the animals were anesthetized with a surgical dose of ketamine and xylazine (listed above) and euthanized with a 1-mL intraperitoneal injection of sodium pentobarbital (Vortech Pharmaceuticals, Dearborn, MI, USA). The animals were perfused intracardially with $2 \%$ glutaraldehyde and $0.15 \mathrm{M}$ cacodylate buffer.

The estimated region of electrode B was selected as the region for histological analysis to ensure that we analyzed the cochlea in a region that was directly adjacent to the electrode array. Before removing the cochlear implant, a small notch in the bone was made with a needle to indicate where electrode $B$ was located. Two implants (animals 335 and 361) were accidentally removed during the ear extraction process so their B location was estimated and based on the average distance from the round window to the $\mathrm{B}$ electrode for the subjects with intact implants. The implanted cochleae were removed, and tissue processing was performed as previously described (Yagi et al. 2000) and then modified as described below. Each cochlea was locally perfused with the glutaraldehyde and cacodylate buffer solution and placed in 3\% ethylenediaminetetraacetic acid (EDTA) solution to decalcify until sufficiently soft for sectioning (approximately 1-2 months). Once decalcified, the implant was removed, and the cochlea was embedded in JB-4 resin (Electron Microscopy Scientific, Washington, PA, USA). Sections were obtained in the para-midmodiolar plane (Kanzaki et al. 2002) and were centered at the location of the notch in the bone that indicated the location of electrode B. These para-midmodiolar sections provided six measurable profiles of Rosenthal's canal (Fig. 2). Sections were cut at a thickness of $3 \mu \mathrm{m}$, and 40 sections were obtained and collected on glass slides, covering a

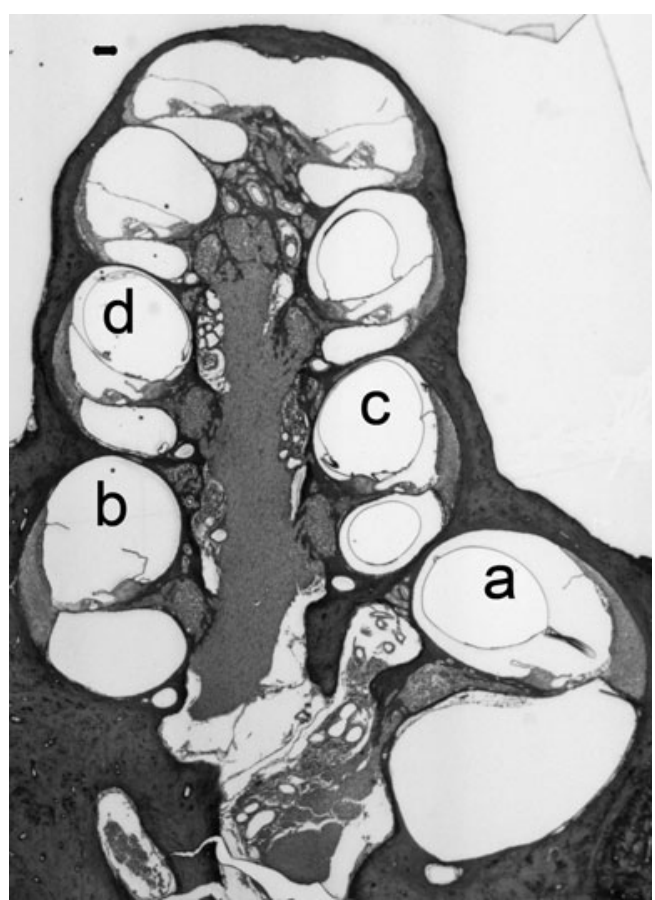

FIG. 2. Light micrograph of a para-midmodiolar section from animal 350 showing areas of histological analysis. The letter designations are in the scala vestibuli, where resin from the sectioning procedure remains in most profiles and in scala tympani in profile " $C$ ". While an imperfect section, it includes the entire cochlea showing regions that were analyzed and those that were not. Profile " $a$ " represented the basal-most profile where the hair cells and neural elements were adjacent to the electrode array. Fibrous tissue remains in the scala tympani in profile " $a$ " where the implant resided. Scale bar (upper left) represents $80 \mu \mathrm{m}$.

length of $120 \mu \mathrm{m}$ along the cochlea spiral. The sections were stained with $1 \%$ toluidine blue in $1 \%$ sodium borate.

\section{Histological analysis}

Histological analysis of the cochleae in all group I animals and three group II animals was performed to assess the hair cell and SGN population. The remaining group II animals that were not analyzed histologically went on to be used in other experiments. Five sections from each animal were selected for histological analysis. The sections were kept in the order that they were obtained from the specimen and numbered 1-40. To avoid bias in selecting the first slide for counting, a random number generator was used to select one section, $n$, from the first eight sections. The next four sections were then selected in increments of eight $(n+8, n+16$, etc. $)$ in order to ensure adequate spacing between sections so as to avoid counting specific cells twice. Each section contained eight profiles of the organ of Corti and six profiles of Rosenthal's canal. Rosenthal's canal was well defined 
by bony borders in the basal-most turns, while the apical-most turn of Rosenthal's canal contained SGNs in a less-well-defined boundary.

We sought to analyze regions of the cochlea adjacent to as well as apical to the electrode array. Thus, we analyzed four profiles of the cochlea and labeled them a, b, c, and d, starting from the basal end of the cochlea (Fig. 2). Profile "a" was the region upon which the para-midmodiolar sections were centered and represents the approximated region occupied by electrode B. Profile "a" is distinct from the remaining three profiles, as profile "a" was the only region analyzed that was adjacent to the electrode array. In contrast, the remaining three profiles (profiles b, c, and d) were apical to the electrode array. Regions apical to profile "d" were difficult to analyze because Rosenthal's canal was not well defined. For the remainder of the manuscript, we consider profile " $a$ " to be synonymous with the analyzed region of the cochlea that was adjacent to the electrode array, specifically the $120-\mu \mathrm{m}$ region that was centered on the approximated location of electrode $\mathrm{B}$.

IHCs, OHCs, and SGN cell bodies were counted in profiles a, b, c, and d. IHCs were counted as present only if a nucleus was present, to prevent double counting. Because of the mosaic pattern of the OHCs, the 3- $\mu \mathrm{m}$ para-midmodiolar sections did not allow all parts of OHCs from all three rows to be seen on every section. Thus, OHCs were counted as present if any portion of a cell body, nucleus, or stereocilia were seen. Since animals in this study were sacrificed many months after implantation, the likelihood of presence of cells that were degenerating at the time of sacrifice is small. We therefore assume that counting OHCs that are not viewed in their entirety does not result in an overestimation of the number of these cells. SGN cell bodies were counted, including only cells with a diameter of $12-25 \mu \mathrm{m}$ with a nucleus between 5 and $9 \mu \mathrm{m}$ in diameter, to prevent cell double counting. The cross-sectional area of Rosenthal's canal was calculated using an Image J computerized image-analysis system, and SGN survival was presented in the form of spiral ganglion packing density $\left(\right.$ cells $\left./ \mathrm{mm}^{2}\right)$. The data from the five sections were averaged to provide an estimate of the status of residual cochlear neural elements for each animal. The percentage of hair cell survival compared to normal was determined by dividing the IHC count by 1.0 and the OHC count by 3.0. The plane of the section and the use of light microscopy did not allow quantitative analysis of the SGN peripheral processes, but a general assessment of their presence or absence in profiles a, b, c, and $d$ was performed. The same histological procedure was used for both group I and group II animals. A single author conducted histological analysis of all subjects and was blinded as to the identity of the subjects.

\section{Statistical analysis}

Initial tests for differences between groups were performed by multivariate analysis of variance using all variables, with SYSTAT (Systat Software, Inc., Point Richmond, CA, USA). SYSTAT performs three multivariate analogs of the $F$ test, which are asymptotically equivalent (Chatfield and Collins 1980). Wilk's lambda and the other equivalent functions were computed for all multivariate analyses, and in all cases, they returned the same $F$ value for a given test within rounding error. Accordingly, we reported only $F$, degrees of freedom, and $p$ values in our results. When a multivariate test was significant $(p<0.05)$, univariate analysis of variance was used to determine which measures contributed to the overall difference, with statistical significance adjusted for multiple comparisons by the sequential Bonferroni adjustment (Rice 1989).

\section{RESULTS}

\section{Histology}

Inner and outer hair cells. The top and middle panels in Figure 3 show the survival of hair cells as a percentage of normal numbers. In group I animals, over $70 \%$ of hair cells were preserved in regions apical to the electrode array with the exception of one animal (374) that suffered greater IHC loss in profile "d" (60\% normal). In profile "a", nine of the 11 group I animals showed at least $75 \%$ survival of IHCs, and six showed at least $75 \%$ survival of OHCs. Thus, even in an area directly adjacent to the electrode array, survival of hair cells was observed in most group I animals. Conversely, in group II animals, no hair cells were present in any of the examined regions of the cochlea.

Figure 4 shows light micrographs of profile "a" in three group I animals and one group II animal. These micrographs display the spectrum of hair cell pathology that we observed in this region. Animal 361 is shown in Figure 4A, displaying complete preservation of the IHC and OHCs. This survival pattern, with evidence of IHC and OHC survival in profile "a", was seen in six of the 11 group I animals (Fig. 3). Three group I animals (335, 347, and 390) showed intermediate pathology, with some evidence of partial OHC degeneration. The extreme of OHC pathology within group I was seen in animal 351, shown in Figure 4B. This micrograph displays the survival of the IHC but complete degeneration of the OHCs. The other subjects with OHC loss (335, 347, and 390) suffered OHC loss to a much milder degree (Fig. 3). Finally, complete degeneration of the organ of Corti was seen in one group I subject, animal 348. Figure 4C 


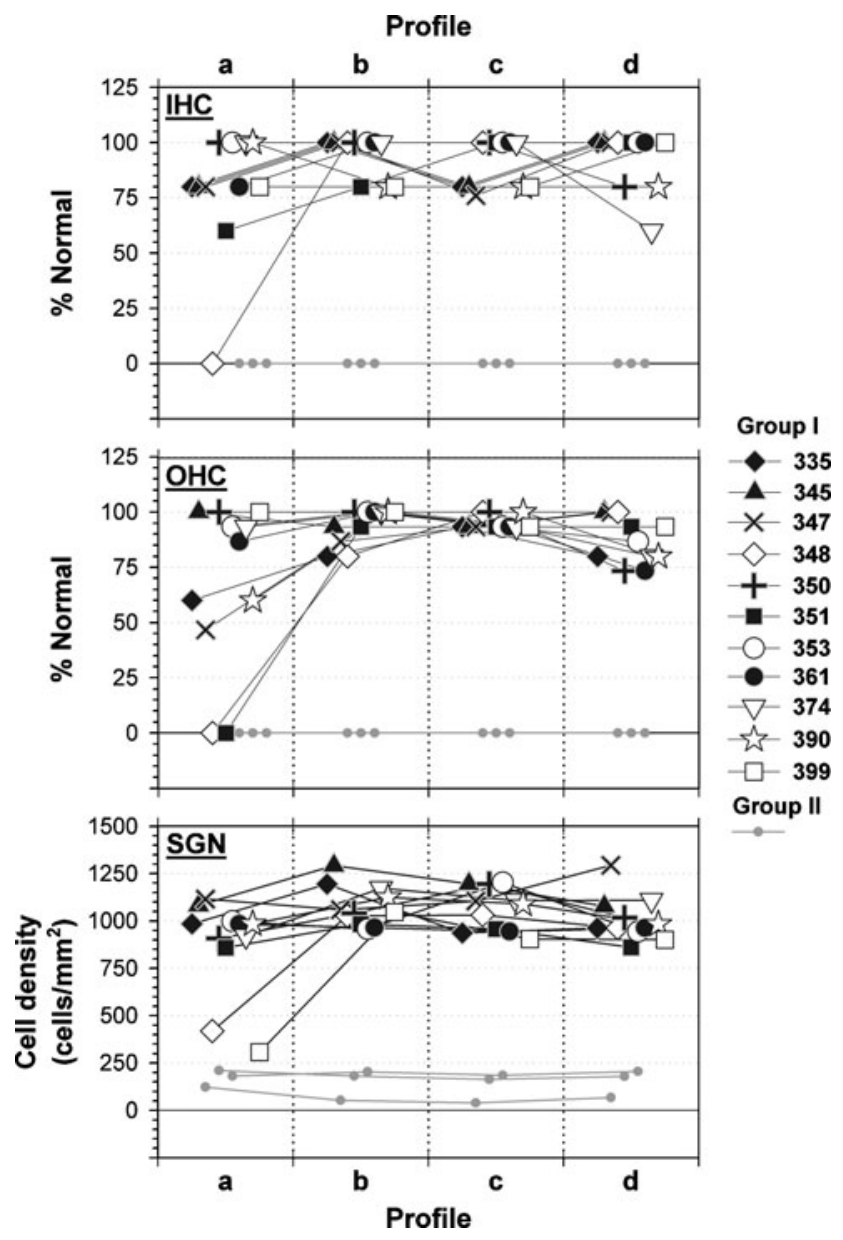

FIG. 3. Inner hair cells $(I H C)$, outer hair cells $(O H C)$, and spiral ganglion neurons $(S G N)$ observed in the four basal-most profiles (ad) of the implanted cochleae. Nine of the 11 group I animals (black symbols) showed survival of hair cells and SGNs adjacent to the electrode array (profile " $a$ "), and all group I animals showed survival of these elements in regions apical to the electrode array (profiles " $b "$ ", "c", and " $d "$ ). The three group II animals that were examined histologically (gray symbols) showed no hair cell survival and lower SGN density. Within each profile, data points on the abscissa are jittered to avoid overlap.

from animal 348 shows the complete absence of hair cells, with some supporting cells that remained. Figure 4D shows the flat epithelium and the absence of hair cells in a group II animal. This finding was consistent in all three group II animals that were examined histologically and with previously published data from neomycin-treated ears (Duckert 1983; Davies et al. 1994; Kim and Raphael 2007).

Spiral ganglion neuron packing density. SGN packing densities in group I animals and three group II animals are shown in the bottom panel of Figure 3. Nine of the group I animals showed SGN densities of at least 850 cells $/ \mathrm{mm}^{2}$ in all examined regions, while two group I animals (348 and 399) showed lower SGN density that was limited to profile "a" (Fig. 3). The three group II animals that were examined showed significantly lower SGN density in all profiles compared to group I animals $(t=4.46$, $d f=12, p=0.0008)$, consistent with a previously published report of SGN loss in guinea pigs several months after ototoxic treatment (Webster and Webster 1981).

Figure 5 shows light micrographs of Rosenthal's canal that display the spectrum of SGN histopathology we observed in profile "a". Animal 350 is shown in Figure $5 \mathrm{~A}$, and represents one of nine group I animals that showed at least 850 cells $/ \mathrm{mm}^{2}$ in all examined regions. Figure 5B shows animal 399, which showed SGN loss in profile "a" despite preservation of hair cells in this region. Figure $5 \mathrm{C}$ shows the micrograph from animal 348, who also suffered SGN loss along with hair cell pathology in the same region. The intracochlear neomycin-treated group II animals showed severe SGN loss in all regions of the examined cochlea in the three cases that were analyzed histologically (Fig. 3). An example of profile "a" from one of these cases is shown in Figure 5D.

Table 1 summarizes the average hair cell survival and SGN density in group I and group II animals. The neomycin-treated group II animals showed a uniform complete loss of hair cells. Loss of SGNs in group II animals was less complete and more variable, but still much greater than that observed in group I animals. As shown in Table 1, Rosenthal's canal was larger in group II animals, but this fact contributed little to the differences in SGN density. Calculating SGN density in group II animals using the average group I crosssectional area of Rosenthal's canal led to a maximum increase in density of 48.2 cells $/ \mathrm{mm}^{2}$.

Spiral ganglion neuron peripheral processes. SGN peripheral processes were present throughout the examined regions of the cochlea in ten of the 11 group I animals. Figure 6 shows light micrographs of profile "a" that display the range of peripheral process survival that was observed in this study. Figure $6 \mathrm{~A}$ from animal 351 illustrates survival of peripheral processes that was representative of ten of the 11 group I animals. Figure $6 \mathrm{~B}$ from animal 348 shows that peripheral processes were notably absent in profile "a", where hair cell loss also occurred in this animal. Another group I subject (361) had an apparent loss of peripheral processes and auditory neurons, but this was limited to the apical-most turn of the cochlea, which was apical to profile "d". No other group I animal exhibited neuronal loss in this apical turn. Degeneration of peripheral processes occurred in all three group II animals that were examined (Fig. 6C). Our para-midmodiolar sections did not allow quantification of the peripheral processes.

Fibrous tissue. A relatively small region of fibrous tissue was present in the scala tympani of profile "a" in all animals. Most of the perilymphatic area remained open, where the implant presumably occupied the 


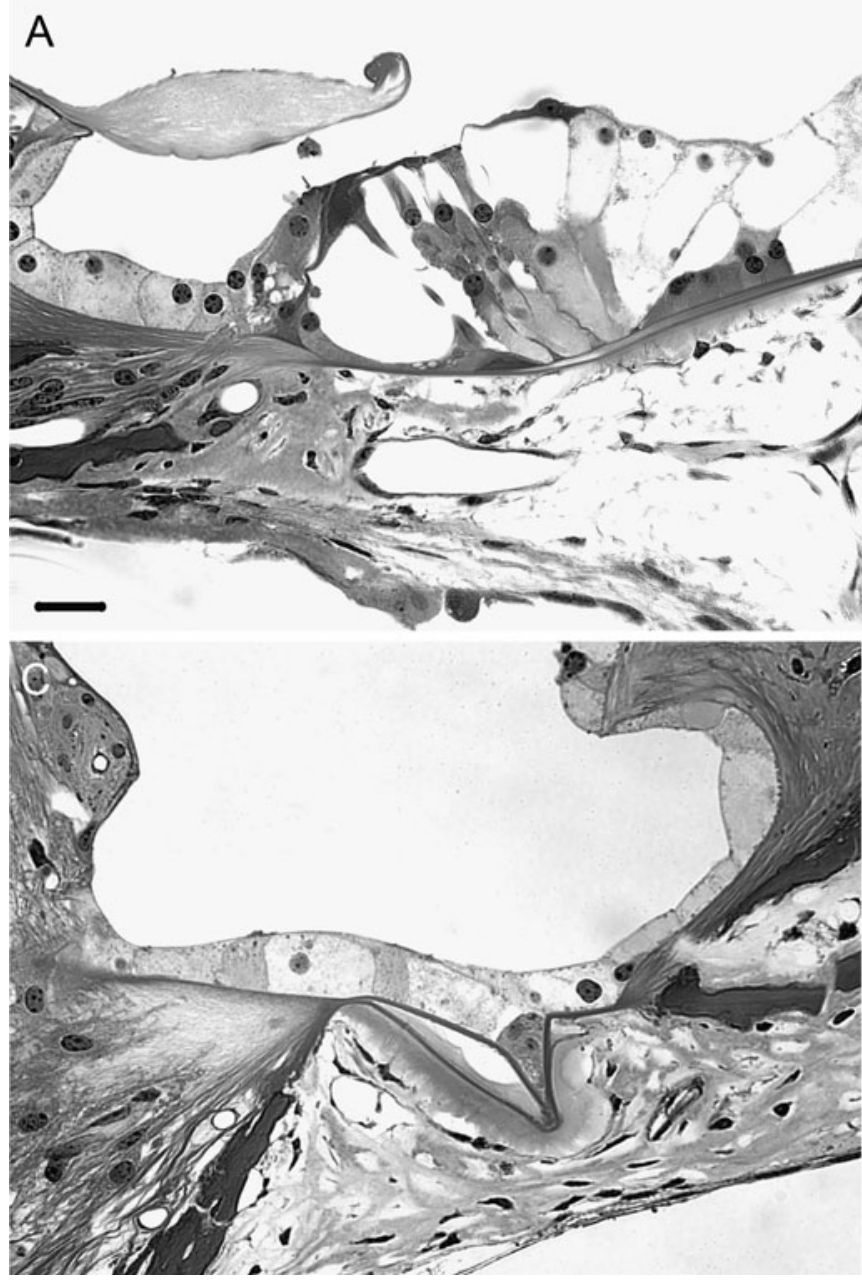

FIG. 4. Light micrographs showing the spectrum of hair cell survival in profile " $a$ " in three group I animals (A-C) and one group II animal (D). Profile " $a$ " was adjacent to the electrode array. A Animal 361, where hair cells were preserved in this region. This survival pattern was representative of six of the 11 group I animals. B Animal 351, which showed complete degeneration of the outer hair

scala tympani. Fibrous tissue can be seen in the scala tympani of profile "a" in Figure 2.

\section{Acoustic thresholds in group I animals}

There was a wide range of psychophysical acoustic thresholds in group I animals following cochlear implantation and electrical stimulation. Figure 7 shows the acoustic detection thresholds (dB SPL) throughout the entire post-implantation period in group I animals. Despite considerable threshold shifts in some animals following implantation, all but one group I animal responded to pure-tone acoustic stimuli at 8,16 , and $24 \mathrm{kHz}$ throughout the entire post-implantation period. The exception (399) had elevated acoustic thresholds at $24 \mathrm{kHz}$ at the beginning of the electrical testing period, and by 130 days, this subject no longer responded to acoustic stimuli at

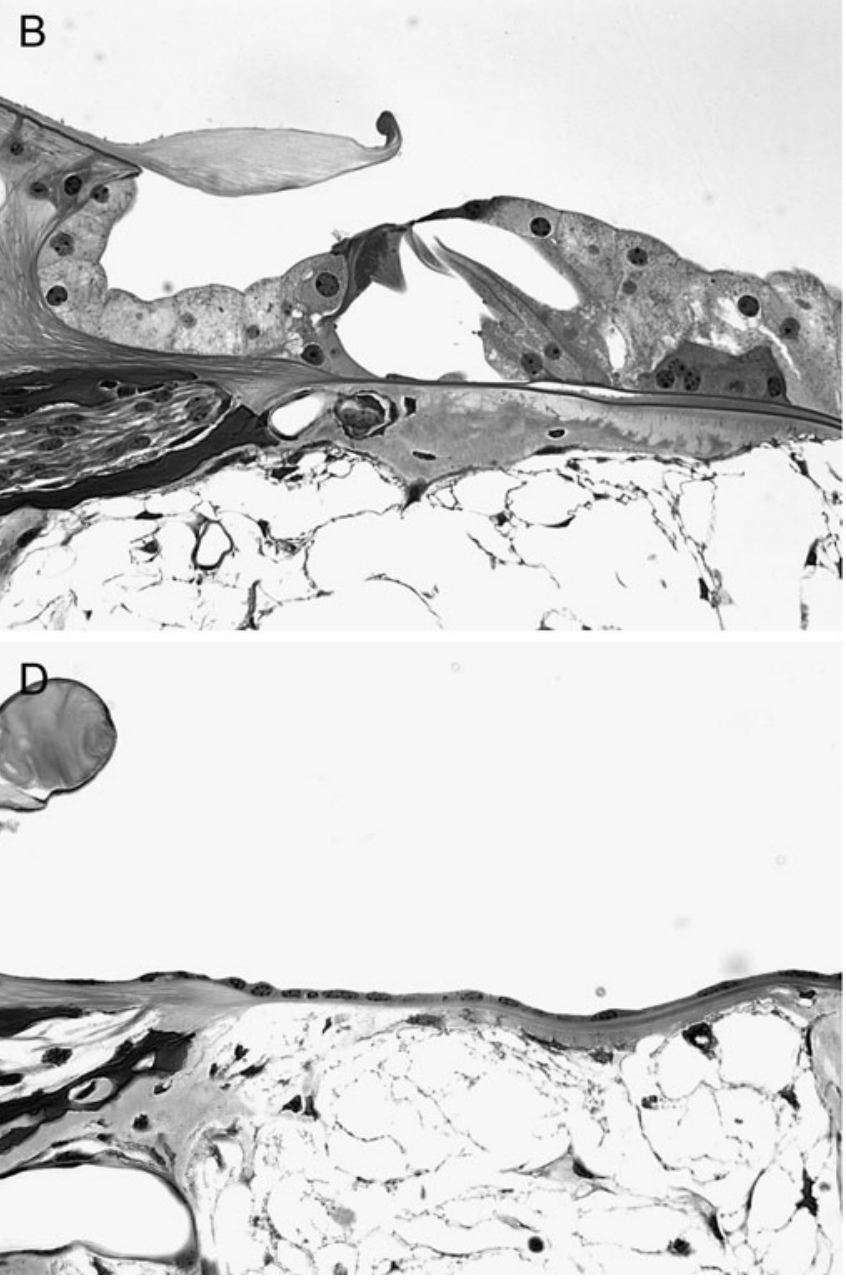

cells $(\mathrm{OHCs})$, with preservation of the inner hair cells. Three other group I animals showed partial OHC degeneration. C Animal 348, which displayed complete loss of hair cells in profile "a". Some supporting cells remained. D Group II animal that showed complete loss of the organ of Corti and a flat epithelium following intracochlear neomycin treatment. Scale bar represents $20 \mu \mathrm{m}$.

that frequency. As discussed above, this subject's histology showed good hair cell survival but low SGN density in profile "a".

\section{Ensemble spontaneous activity}

ESA in the auditory nerve was present in all group I animals, evidenced by a spectral peak between 900 and $1,000 \mathrm{~Hz}$ (Fig. 8). Four group II animals also underwent ESA testing but failed to show evidence of spontaneous activity, exhibited by the absence of the peak at around $900 \mathrm{~Hz}$. A quantitative assessment of the spectral peaks is provided in Table 2. Higher peak response levels were observed in group I animals, and this difference was statistically significant $(t=9.33$, $d f=13, p<0.0001)$. The average peak response level for group I animals was $-33.4 \mathrm{dBv}$, with a standard deviation of $1.84 \mathrm{dBv}$. The average peak response level 

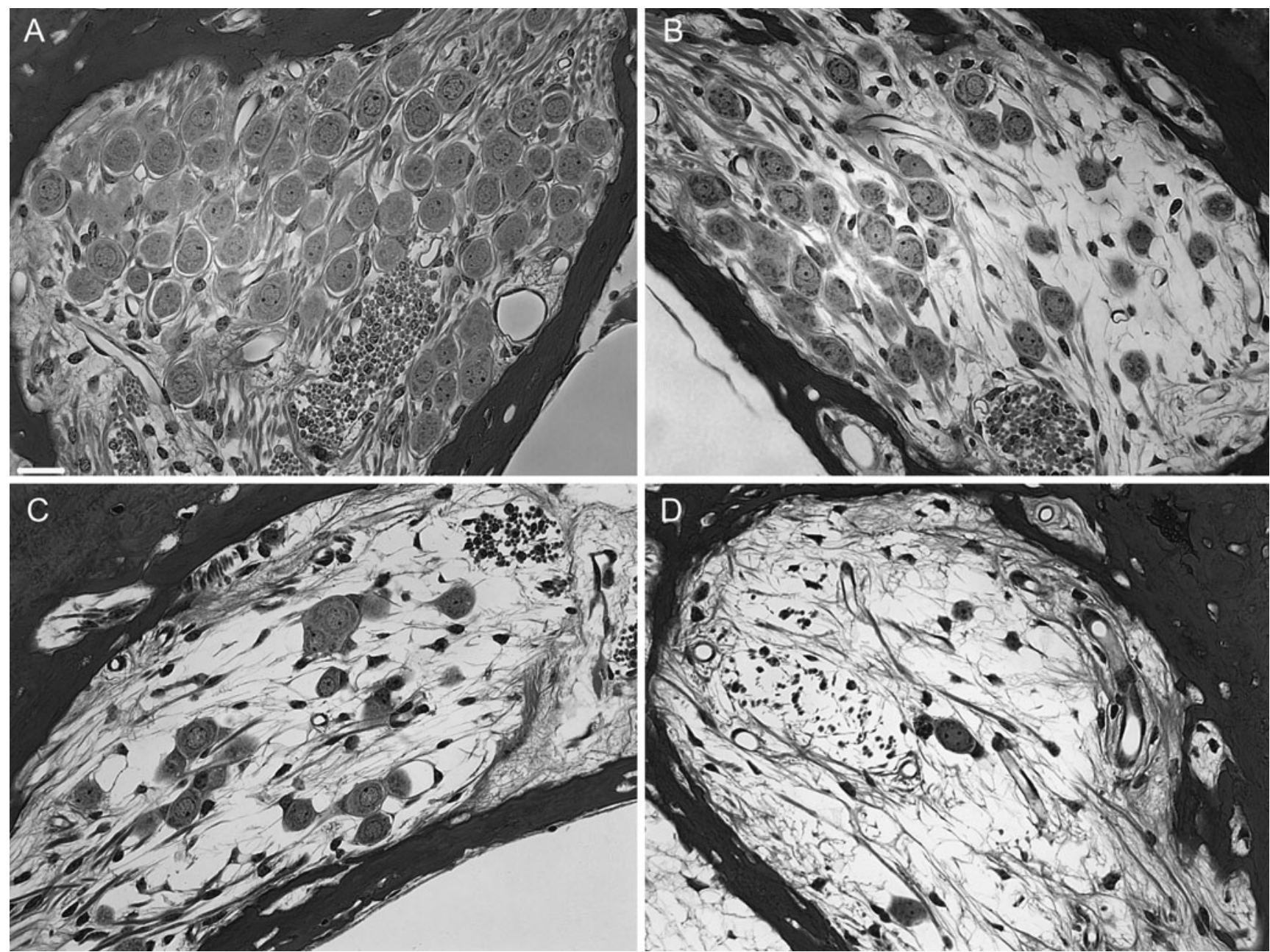

FIG. 5. Light micrographs showing the spectrum of spiral ganglion neuron (SGN) cell body survival in profile " $a$ " in three group I animals (A-C) and one group II animal (D). Profile " $a$ " was adjacent to the electrode array. A Animal 350, which displayed an SGN survival of 907.6 cells $/ \mathrm{mm}^{2}$. B Animal 399, which showed a surprising reduction in SGNs (306.7 cells $/ \mathrm{mm}^{2}$ ) despite having surviving hair cells in the region. C Animal 348, showing SGN

for group II animals was $-44.4 \mathrm{dBv}$, with a standard deviation of $2.50 \mathrm{dBv}$.

The three animals with the highest response levels (345, 353, and 374) also had the lowest acoustic thresholds, consistent with the idea that the ears with the best functioning hair cells produced the highest ESA levels. The ESA amplitude around $900 \mathrm{~Hz}$ for animal 348 was the lowest of the response levels for the group I animals. In this animal, the peak was likely due to auditory nerve fibers apical to the implant because it is unlikely that fibers near the implant would be spontaneously active in the absence of hair cells and peripheral processes.

\section{Electrical thresholds in group I and group II}

Pulse-train stimuli. In response to the electrical pulsetrain stimuli $(0.02 \mathrm{~ms} /$ phase $)$, the detection thresholds

reduction $\left(418.6\right.$ cells $\left./ \mathrm{mm}^{2}\right)$ in the same region in which degeneration of hair cells occurred. D Group II animal, with severe degeneration of SGNs following intracochlear neomycin treatment. The average SGN density of the group II animals was 171.9 cells/ $\mathrm{mm}^{2}$. The selection of subjects does not necessarily coincide with Figure 4 . Scale bar represents $20 \mu \mathrm{m}$.

of most group I animals were lower than those for group II (neomycin-treated) animals at all pulse rates. Each animal's thresholds for stimulation at site 1 and site 2 are shown in Figure 9. At site 1, three group I animals (348, 361, and 399) had relatively high thresholds that were similar to those seen in group II animals. At site 2, only the thresholds for animal 348 were within the range of those for the group II animals, while the thresholds of animals 399 and 361 were somewhat lower.

There were no significant differences in thresholds for electrical pulse-train $(F=0.417, d f=5$ and 4 , $p=0.818)$ or electrical-sinusoid stimuli $(t=0.32, d f=8$, $p=0.76$ ) associated with neomycin treatment of the contralateral ear in group II animals, so the data for these two subgroups (treated versus nontreated in the ear contralateral to the implant) were analyzed as one group (group II). 
TABLE 1

Summary of group I (non-neomycin-treated) and group II (neomycin-treated) histological data for profiles a, b, c, and d

\begin{tabular}{|c|c|c|c|c|}
\hline & a & $b$ & c & $d$ \\
\hline \multicolumn{5}{|l|}{ Group I } \\
\hline Average IHC per profile & 0.8 & 0.9 & 0.9 & 0.9 \\
\hline std & 0.3 & 0.09 & 0.1 & 0.1 \\
\hline Average $\mathrm{OHC}$ per profile & 2.0 & 2.8 & 2.9 & 2.6 \\
\hline std & 1.14 & 0.24 & 0.09 & 0.32 \\
\hline Average SGN density (cells/mm²) & 869.3 & $1,078.7$ & $1,061.1$ & $1,007.1$ \\
\hline std & 262.0 & 106.2 & 112.6 & 119.0 \\
\hline Average $\mathrm{RC}$ area $\left(\mu \mathrm{m}^{2}\right)$ & $34,100.5$ & $29,504.4$ & $31,654.7$ & $27,204.3$ \\
\hline std & $5,117.7$ & 4,992.5 & $5,406.5$ & 3,137.9 \\
\hline \multicolumn{5}{|l|}{ Group II } \\
\hline Average IHC & 0 & 0 & 0 & 0 \\
\hline std & 0 & 0 & 0 & 0 \\
\hline Average $\mathrm{OHC}$ & 0 & 0 & 0 & 0 \\
\hline std & 0 & 0 & 0 & 0 \\
\hline Average SGN density (cells/mm²) & 171.9 & 146.3 & 129.7 & 150.7 \\
\hline std & 44.4 & 81.7 & 78.8 & 73.1 \\
\hline Average $\mathrm{RC}$ area $\left(\mu \mathrm{m}^{2}\right)$ & $43,763.4$ & $34,502.5$ & $34,665.4$ & $28,517.0$ \\
\hline std & 8,999.9 & $3,771.0$ & $1,040.4$ & $1,653.1$ \\
\hline
\end{tabular}

At site 1, the multivariate analysis of variance found that thresholds in group I animals were significantly lower $(F=5.73, d f=5$ and $15, p=0.004)$, and post hoc $F$ tests showed significant differences between groups at each pulse rate, even after Bonferroni adjustment of the critical alpha for the number of tests was performed $(F \geq 16.0, d f=1$ and $19, p \leq 0.002)$. Results for site 2 also showed lower thresholds in group I for the combined data $(F=12.03, d f=5$ and $14, p<0.001)$ and for each pulse rate tested separately $(F>47.0, d f=$ 1 and 18, $p<0.001)$. The analysis did not include 5,000 pps because two group II animals were not tested at this pulse rate.

In addition to the differences in threshold levels, the slopes of the threshold versus pulse rate functions also differed between groups. Group I animals displayed steady decreases in threshold as the pulse rate increased (Fig. 9), resulting in a relatively uniform slope in the threshold versus pulse rate function (Fig. 10). In contrast, below 1,000 pps, group II animals displayed little or no decrease in threshold as the pulse rate increased. Above 1,000 pps, thresholds for group II animals showed decreases in threshold as a function of pulse rate similar to those observed in group I animals. As shown in Figures 9 and 10, the main differences in the slopes of the threshold versus pulse rate functions occurred at pulse rates below 1,000 pps, where at site 1, the average slope for group I animals was $-1.84 \mathrm{~dB} /$ doubling while the average for group II animals was $-0.52 \mathrm{~dB} /$ doubling. At these same pulse rates, results from stimulation at site 2 were similar: the average slopes for group I and group II animals were $-2.46 \mathrm{~dB} /$ doubling and $-0.61 \mathrm{~dB} /$ doubling, respectively.
Sinusoidal stimuli. The $100-\mathrm{Hz}$ sinusoidal stimuli showed a trend opposite to that seen with the pulsetrain stimuli. At both stimulation sites, the detection thresholds were lower in most group II (neomycintreated) animals than in group I animals (Fig. 11). Multivariate analysis of variance of the psychophysical thresholds at sites 1 and 2 showed that the thresholds were significantly different between groups $(F=10.65$, $d f=2$ and 18, $p=0.0009$ ), and post hoc univariate $F$ tests showed that thresholds were significantly different at both site $1 \quad(F=22.46, d f=1$ and 19 , $p=0.0001)$ and site $2(F=16.32, d f=1$ and $19, p=0.0007)$.

\section{Electrical impedances}

The average values of the impedances measured for group I and group II animals during the period when the electrical thresholds were obtained are shown in Table 3. On average, impedances for group II were higher than those for group I. Group II contained one outlier at site 1 . This impedance value was over five times the value of the group average, resulting in the high mean and large standard deviation. The group II subject with the high impedance values had psychophysical data that were consistent with those of other group II animals. Table 3 shows the average impedance values for group II animals including and excluding this subject.

Multivariate analysis of variance of the impedances at site 1 and site 2 showed a significant difference between groups $(F=13.51, d f=2$ and $17, p=0.0003)$, and post hoc univariate $F$ tests showed that impedances were significantly different at site $2(F=23.68, d f=1$ 


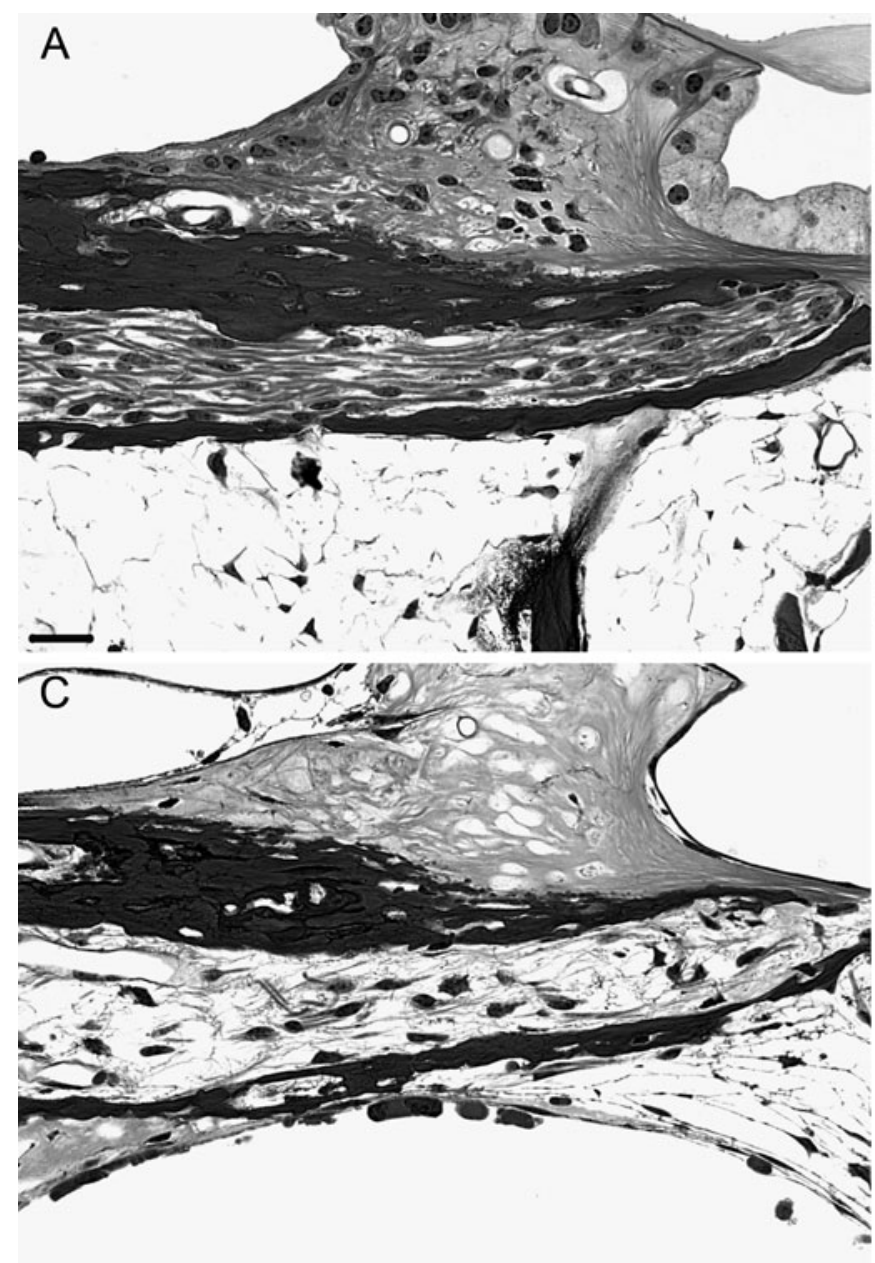

FIG. 6. Light micrographs showing the extent of peripheral process survival in group I and group II animals in profile " $a$ ". Profile " $a$ " was adjacent to the electrode array. A Animal 351, with well-preserved peripheral processes in this region, which was representative of ten of the 11 group I animals. B Animal 348, which was the only group I

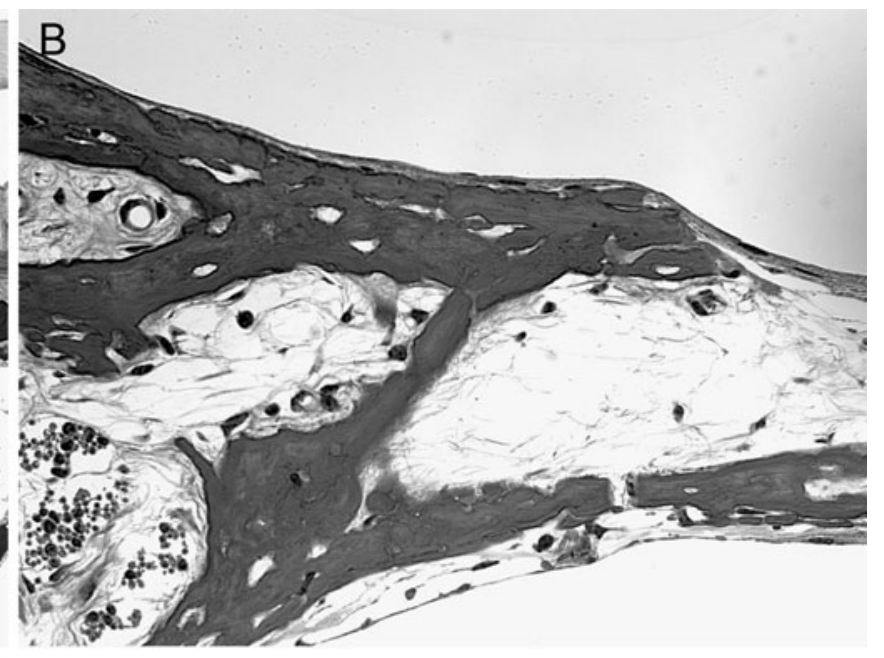

and 18, $p=0.0001)$ but not at site $1(F=2.19, d f=1$ and $18, p=0.16)$. Excluding the outlier in group II, the difference between groups was still significant $(F=11.51, d f=2$ and $16, p=0.0008)$, and post hoc univariate $F$ tests showed that impedances at site 1 were again not significantly different $(F=4.29, d f=1$ and 17 , $p=0.0538$ ). There were no trends between the impedance data and the psychophysical data within groups.

\section{Exceptional cases in group I}

As shown in Figure 3, our treatment and implantation procedure preserved hair cells and SGNs in most group I animals and achieved marked differences in auditory neuronal survival between groups I and II. Groups I and II also displayed marked differences in electrical hearing in response to sinusoidal and pulsetrain stimuli. Examination of two group I animals that suffered some degree of pathology in profile "a" animal that showed degeneration of the peripheral processes. C Group II animal, showing a marked decrease in nerve fibers in this region. Quantification of peripheral processes was not possible in these para-midmodiolar sections. Scale bar represents $20 \mu \mathrm{m}$.

might provide more information on the effects of hair cell and auditory neuron survival on the perception of electrical stimuli, although the number of animals with these patterns of hair cell and SGN pathology is too small to draw definitive conclusions.

Animal 348 had severe pathology: no surviving hair cells and only 419 cells $/ \mathrm{mm}^{2}$ of SGN survival in profile "a". Electrical threshold levels for pulse trains and $100 \mathrm{~Hz}$ sinusoids in this animal were indistinguishable from those of the group II animals. Furthermore, this animal had threshold versus pulse rate function slopes at both stimulation sites that resembled those of group II animals, with shallow slopes below $1,000 \mathrm{pps}$ and steeper slopes above 1,000 pps (Fig. 9). Because this animal had near normal numbers of hair cells and SGNs apical to profile "a", it is likely that the condition of the hair cells and/or auditory neurons in the immediate vicinity of the implant affected these electrical thresholds. 

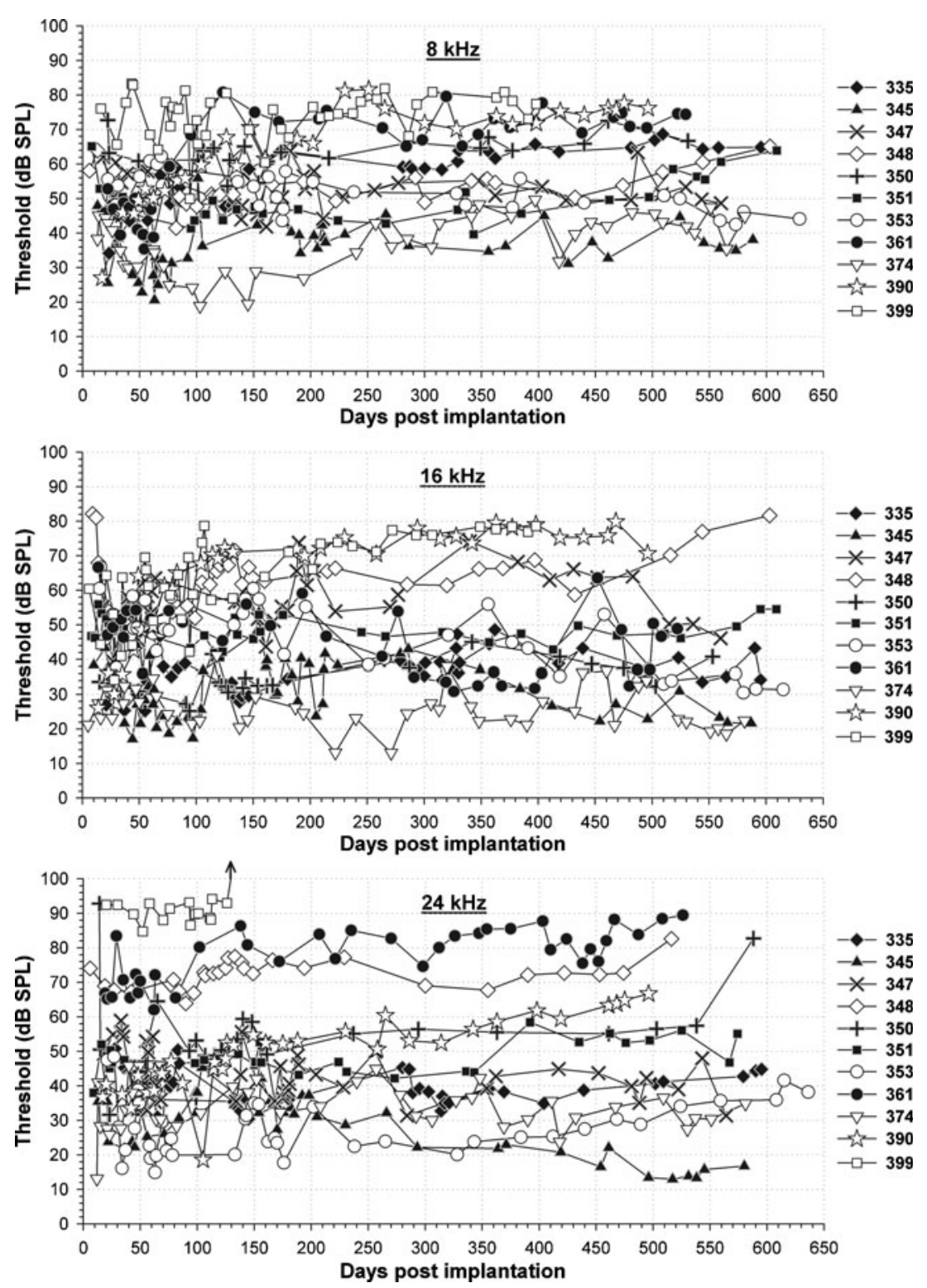

FIG. 7. Acoustic psychophysical thresholds in group I animals following cochlear implantation. With the exception of one animal, all group I animals showed psychophysical responses to acoustic stimuli throughout the post-implantation period. Animal 399 failed to respond to acoustic stimuli at $24 \mathrm{kHz}$ at approximately 130 days post-implantation. Although there were considerable threshold elevations following cochlear implantation and some fluctuations throughout the electrical stimulation period, this figure illustrates that the majority of group I animals maintained the ability to respond to acoustic stimuli up to 21 months after cochlear implantation.
Animal 399 also had a relatively low SGN density (307 cells $/ \mathrm{mm}^{2}$ ) but near normal IHCs and OHCs in profile "a". The threshold versus pulse rate function for site 1 in animal 399 was similar to those of group II animals in levels and slopes (Fig. 9, top panel, open squares), whereas for site 2, the pulse-train threshold levels and threshold versus pulse rate function were like those of the majority of the other group I animals (Fig. 9, bottom panel). Thresholds for $100 \mathrm{~Hz}$ sinusoids at both sites were indistinguishable from those of the group II animals. This suggests that loss of SGNs in this subject, rather than hair cell loss, resulted in the group II-type response for the threshold versus pulse rate functions.

Animal 361 was puzzling. This animal had pulse rate versus threshold functions similar to those of group II animals at site 1, yet showed preservation of hair cells, peripheral processes, and SGN cell bodies. In the current analysis, we cannot explain this subject's psychophysical data based on the existing histological data. However, we note that the acoustic thresholds for animal 361 were relatively high, especially for the 8 - and $24-\mathrm{kHz}$ tones. These high acoustic thresholds might have been due to hair cell or spiral 


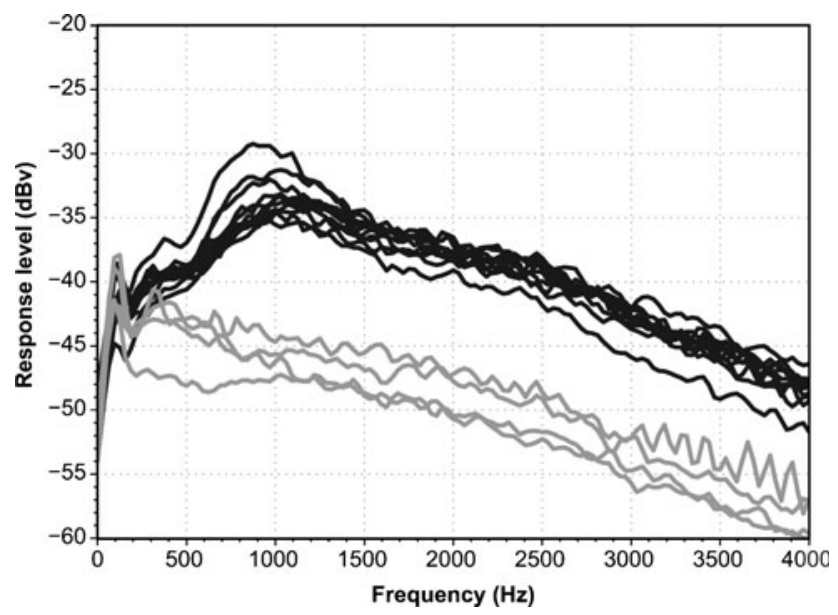

FIG. 8. Spectrum of ensemble spontaneous activity (ESA) recordings from 11 group I animals (black traces) and four group II animals (gray traces). The traces show spectral peaks between 900 and $1,000 \mathrm{~Hz}$ in all group I animals (black), suggesting spontaneous firing of the auditory nerve. None of the tested group II animals (gray) exhibited peaks between 900 and 1,000 Hz, suggesting that the auditory nerve fibers in the region of testing had little or no spontaneous activity.

ganglion cell pathology not revealed in our lightmicroscope analysis of the tissue or to mechanical disruption of basilar membrane motion due to the physical presence of the implant. Either case would be disruptive to electrophonic hearing, and this might explain the group II-like results as discussed below in the "Discussion" section.

\section{DISCUSSION}

\section{Histopathology}

Our results show that it is possible to insert an electrode array into a normal guinea pig cochlea and deliver electrical stimulation over a time period as long as 21 months, while preserving cochlear structures in regions adjacent to as well as apical to the electrode array. The ability of group I animals to respond to acoustic stimuli demonstrates that the surviving hair cells and neural elements were functional. Despite threshold elevations following implantation, ten of 11 group I animals responded to acoustic stimuli throughout the duration of the study. The threshold elevations might have been due to pathology of some of the surviving hair cells and neurons and/or to disruption of cochlear mechanics by the presence of the implant in the scala tympani.

In the animals that showed pathology in profile "a", it is important to consider the potential mechanism of cellular injury. Cochlear pathology might have been a result of the chronic electrical stimulation or trauma induced during insertion of the electrode array. Recent human studies that investigated combined acoustic and electrical hearing suggest that the key to preserving residual acoustic hearing following cochlear implantation is to limit the amount of cochlear trauma induced during electrode insertion (James et al. 2005; Berrettini et al. 2008). However, it is possible that electrical stimulation itself may cause hair cell and SGN loss. Some studies have shown that electrical stimulation is capable of causing degenerative changes in the cochlea (Walsh et al. 1981; Duckert and Miller 1982; Duckert 1983), while other studies indicate that hair cells are not adversely affected by electrical stimulation (Ni et al. 1992; Xu et al. 1997). Electrically induced pathology appears to be dependent on the charge density of the electrical stimulus.

This study differs from the animal studies mentioned above in two important respects: in the current study, the total implantation period was significantly longer but the amount of stimulation received on any given day was considerably less. Because of the nature of our study (measuring psychophysical thresholds), it is not possible to make a uniform statement regarding the charge density of the electrical stimulus. Each animal was exposed to a distinct maximum charge density depending on the electrical threshold. Furthermore, the maximum charge density for each animal was only employed during the immediate post-implantation period prior to threshold stabilization. Thus, unlike the studies cited above, our study was not designed to determine the effects of charge density on hair cell survival. However, the animals with the highest thresholds required the most current, and the largest amount of charge density was given with the $100-\mathrm{Hz}$ sinusoidal stimuli due to its phase duration.

\section{TABLE 2}

Peak response levels $(\mathrm{dBv})$ from the ensemble spontaneous activity (ESA) traces from Figure 8 are shown along with the frequency at which the peak response levels were observed in each animal

\begin{tabular}{cccc}
\hline & Animal & Peak response level $(\mathrm{dBv})$ & Frequency $(\mathrm{Hz})$ \\
\hline Group I & 345 & -29.2 & 875 \\
& 353 & -31.5 & 969 \\
& 374 & -32.0 & 969 \\
& 350 & -33.3 & 938 \\
& 390 & -33.5 & 938 \\
& 399 & -33.9 & 969 \\
& 335 & -34.0 & 969 \\
& 347 & -34.6 & 969 \\
& 351 & -35.0 & 969 \\
Group II & 361 & -35.0 & 906 \\
& 348 & -35.3 & 969 \\
& 406 & -42.3 & 656 \\
& 400 & -42.6 & 531 \\
& 360 & -44.9 & 531 \\
\hline
\end{tabular}

Peak response levels were markedly higher in group I animals in comparison to the four group II animals that underwent ESA recording 


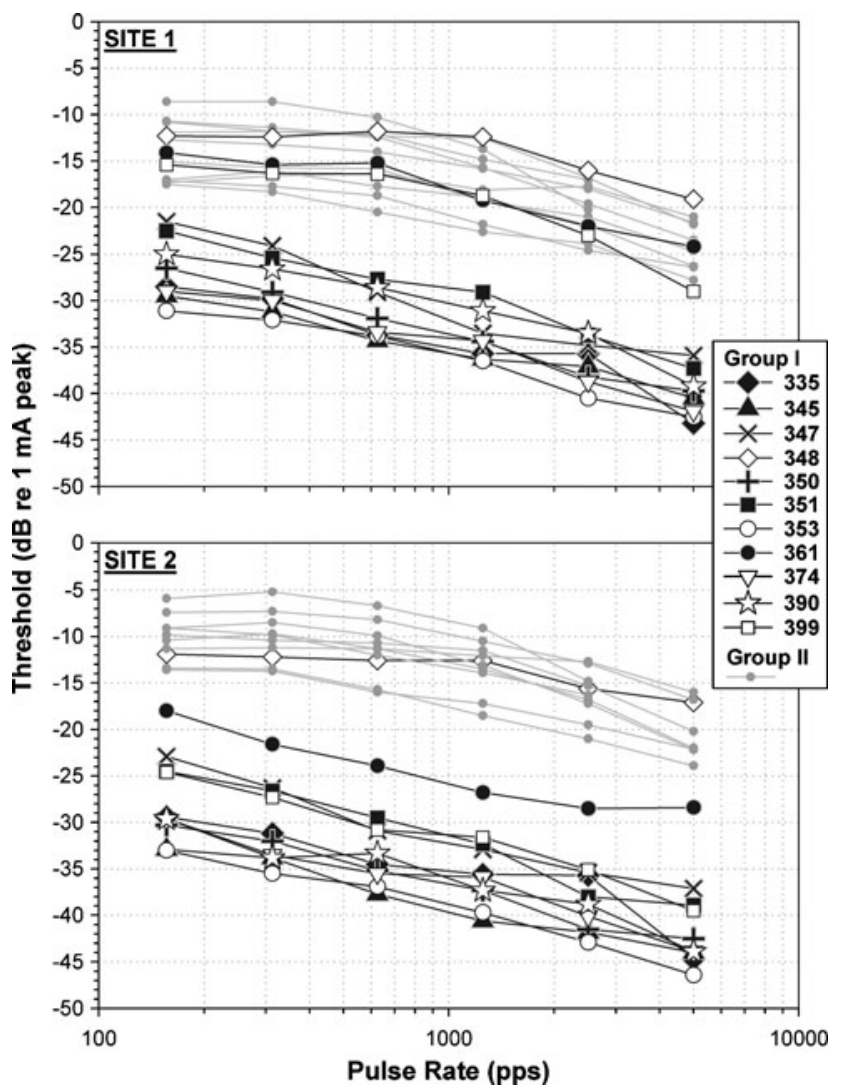

FIG. 9. Psychophysical detection thresholds for trains of $0.02 \mathrm{~ms} /$ phase biphasic pulses at pulse rates of 156, 313, 625, 1,250, 2,500, and 5,000 pps at site 1 and site 2. For site 1, most group I animals (large symbols in black) had lower detection thresholds and steeper threshold versus pulse rate functions at low pulse rates than group II animals (small circles in gray). Three group I animals had thresholds within the range of group II animals. Site 2 results are similar, with most group I animals having lower thresholds than group II animals. However, of the three group I animals that showed elevated thresholds at site 1 , only a single group I animal had functions similar to the functions of group II animals at site 2 .

The three animals (348, 351, and 399) that demonstrated the most pathology had relatively low thresholds with this stimulus and were exposed to lower charge densities than other group I animals that failed to show marked cochlear pathology. Thus, the cochlear pathology in animals 348, 351, and 399 was most likely due to insertion trauma rather than excessive electrical stimulation. The most intriguing and encouraging finding of the histological analysis was the survival of hair cells, peripheral processes, and SGN cell bodies in most group I animals that were implanted and electrically stimulated for well over 1 year.

\section{Psychophysical responses to cochlear implant stimulation}

The effects of hearing preservation on the threshold versus pulse rate functions were of particular interest in this study. The neural representation of electrical pulse trains is essential to the performance of cochlear implants since these pulse trains serve as the carrier for the temporal envelopes that convey much of the information needed for speech recognition. The condition of the hair cells and auditory neurons near the stimulating electrodes might affect the manner in which the auditory system integrates the responses to electrical pulses by influencing the number of surviving stimulable fibers as well as temporal properties of those fibers, affecting adaptation, refractory properties, and/or the amount of across-fiber synchrony in the stimulated fibers (Shepherd and Javel 1997; Vischer et al. 1997; Wilson et al. 1997; Matsuoka et al. 2000; Miller et al. 2001; Hu et al. 2003; Cartee et al. 2000, 2006; Prado-Guitierrez et al. 2006).

Group I animals had lower thresholds (better sensitivity to the electrical stimuli) than the neomycin-treated group II animals when $0.02 \mathrm{~ms} /$ phase pulse-train stimuli were used. In addition to the

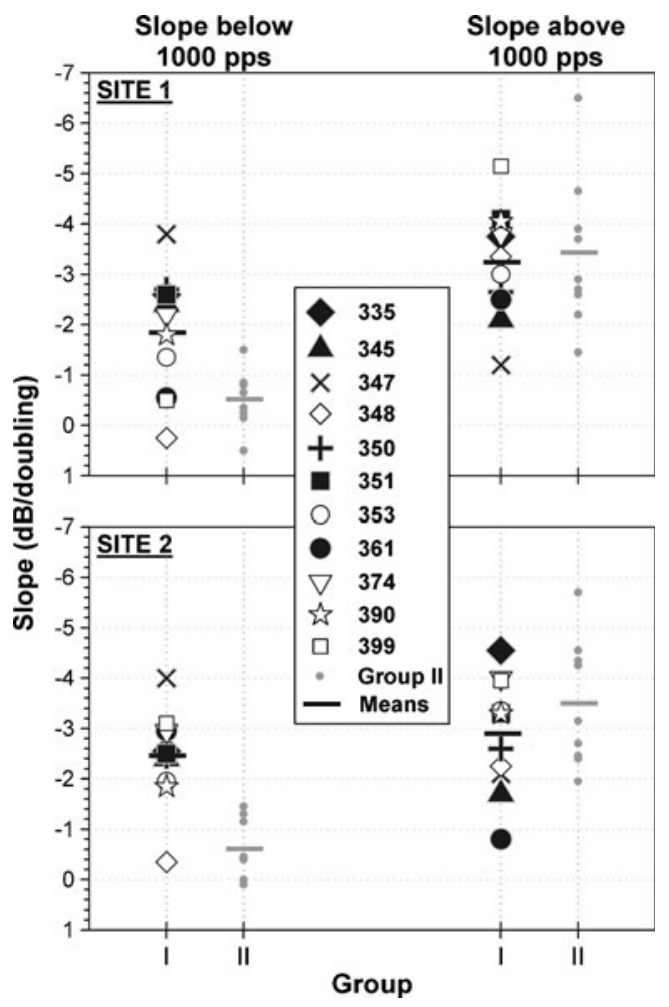

FIG. 10. Slopes of the threshold versus pulse rate functions at pulse rates below 1,000 pulses per second (pps; left columns) and above 1,000 pps (right columns). Below 1,000 pps, group I animals (large symbols in black) showed a greater decrease in threshold with each doubling of the pulse rate than group II animals (small circles in gray). At pulse rates below 1,000 pps, the mean slopes of group I animals were outside of the complete range of slopes for group II animals. However, above 1,000 pps, there were no consistent differences between groups in the slopes of the threshold versus pulse rate functions. This was observed at both site 1 and site 2 . In two group II animals where the 5,000 pps rate was not tested, the slopes between the 1,250- and 2,500-pps thresholds were used. The mean slopes for each group and condition are represented by bars. 


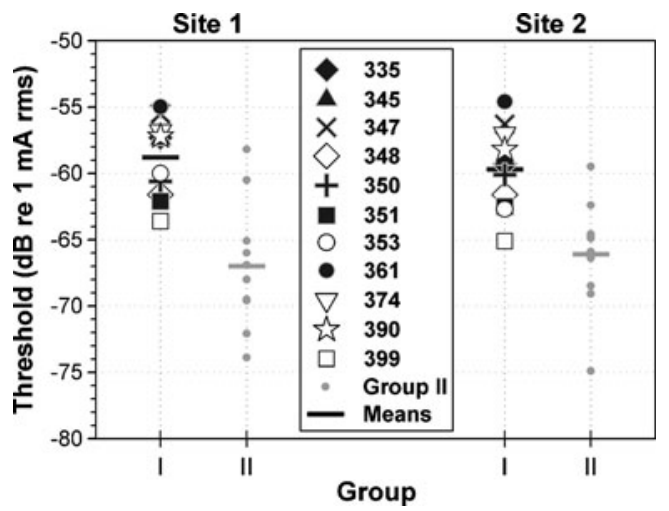

FIG. 11. Psychophysical detection thresholds for the $100-\mathrm{Hz}$ sinusoidal stimulus at site 1 (left columns) and site 2 (right columns). With this stimulus, detection thresholds were lowest in most group II (neomycin-treated) animals at both stimulation sites. Average group thresholds are indicated by bars, individual group I animal thresholds are indicated by large symbols in black, and group II animal thresholds are indicated by small circles in gray.

threshold-level differences, groups I and II showed differences in the slopes of the threshold versus pulse rate functions below 1,000 pps. Group I animals had relatively uniform threshold versus pulse rate functions in which the threshold consistently decreased with each doubling of the pulse rate. Group II animals displayed a threshold versus pulse rate function in which thresholds showed little or no decrease with doubling of the pulse rate at pulses below 1,000 pps, but showed greater decreases in threshold at higher pulse rates. Notably, this resulted in a function with a horizontal slope at lower pulse rates and a steeper slope at higher pulse rates similar to that reported by Middlebrooks (2004) for cortical neural thresholds in guinea pigs that had received cochlear perfusion of neomycin. The similarity of the psychophysical and auditory-cortex data suggests that the psychophysical functions observed in our study were indeed responses to stimulation of auditory neurons. The animal in group I who suffered complete loss of hair cells and peripheral processes and reduced density of SGN cell bodies in profile "a" (348) showed pulsetrain threshold levels and threshold versus pulse rate functions at both stimulation sites that were very similar to those of the group II animals. This suggests that the preservation of hair cells and/or SGNs near the implant (profile "a") is responsible for the behavioral differences observed in this study.

With regard to absolute electrical thresholds, a surprising finding of this study was that the neomycintreated group II animals had significantly lower thresholds than group I animals in response to the $100-\mathrm{Hz}$ sinusoidal stimuli, while the opposite trend was observed with pulsatile stimuli. Thus, the preservation of hearing in group I animals did not have a uniform effect on electrical psychophysical thresholds, suggesting that inherent characteristics of the stimulus type such as phase duration and frequency interacted with the preservation of hearing to affect the psychophysical results. Therefore, the mechanism by which hearing preservation affected the perception of electrical stimuli must explain (a) why the two treatment groups had significantly different electrical thresholds and (b) why the effect of hearing preservation on electrical thresholds depended upon the type of electrical stimulus tested. We propose several mechanisms that might contribute to our psychophysical observations.

Number of surviving neurons. Histological results from this study indicate much better SGN survival in group I animals compared to the three histologically examined animals from group II and compared to previously reported data from neomycin-treated ears. Intuitively, one might expect that better nerve survival would be correlated with lower electrical-detection thresholds. There are some data to support this supposition in cases where no healthy surviving hair cells were present in the implanted ears (Pfingst and Sutton 1983; Chikar et al. 2008). However, in the present study, we found that the differences in threshold between group I and II depended on the temporal characteristics of the electrical stimulus, with thresholds for $100 \mathrm{~Hz}$ electrical sinusoids actually being lower in the group with poor nerve survival. A similar result for thresholds for $100 \mathrm{~Hz}$ stimuli was found in a previous study that included a comparison of neomycin-treated and non-treated implanted cochleae ( $\mathrm{Su}$ et al. 2008). Thus, for cases with preserved hearing, additional mechanisms that might explain our results should be considered.

Spontaneous activity. IHCs are capable of creating spontaneous activity in the auditory nerve (Sewell 1984), which can affect the way in which the nerve responds to electrical stimulation (Wilson 1997; Haenggeli et al. 1998; $\mathrm{Hu}$ et al. 2003). If hair cells

TABLE 3

Electrical impedances $(\mathrm{k} \Omega)$ for group I and group II animals during the collection of psychophysical data

\begin{tabular}{lll}
\hline & \multicolumn{1}{c}{ Site 1 } & \multicolumn{1}{c}{ Site 2 } \\
\hline Group I average & 7.4 & 8.9 \\
Range & $5.8-13.8$ & $4.1-13.1$ \\
Standard deviation & 2.3 & 2.7 \\
Group II average & 22.2 & 15 \\
Range & $4.4-118.9$ & $11.3-20.2$ \\
Standard deviation & 34.4 & 2.9 \\
Group II average & 11.4 & 15 \\
(excluding outlier) & & \\
Range & $4.4-22.3$ & $11.3-20.2$ \\
Standard deviation & 5.8 & 2.9 \\
\hline
\end{tabular}


are present and creating spontaneous activity in the auditory nerve, at any given time, a subpopulation of nerve fibers will be spontaneously firing and will subsequently be in a refractory state while another subpopulation of nerve fibers is ready for depolarization. Conversely, in a deafened cochlea, the auditory nerve is silent in the absence of external stimulation, and electrical stimulation results in abnormally high acrossfiber synchrony that can affect the encoding of temporal detail in the response to the electrical stimulus. Hu et al. (2003) found that the electrically evoked compound action potential (ECAP) amplitude of the first pulse in a pulse train increased after furosemide treatment and decreased after recovery from the treatment. Furthermore, they found that the ratio of the amplitude of the second pulse in the train relative to the amplitude of the first pulse decreased with furosemide treatment, thus demonstrating a clear relationship between hair cell function and ECAP responses and suggesting that furosemide treatment resulted in increased across-fiber synchrony and/or an increase in the number of responding fibers.

Our results showed evidence of spontaneous activity in all group I animals. No evidence of spontaneous activity was observed in group II animals that we tested. The presence of spontaneous activity could affect the interactions of responses to adjacent electrical pulses and the number of fibers firing to any given pulse and thus affect the levels and slopes of threshold versus pulse rate functions. In this study, we observed distinct differences in threshold versus pulse rate functions between treatment groups. It would also be reasonable to speculate that neomycin treatment and subsequent increased across-fiber synchrony would result in stimulus detection at lower levels. However, it is not clear if or why the presence of spontaneous activity would result in higher thresholds for one type of stimulus (100 Hz sinusoids) but lower thresholds for another type $(0.02 \mathrm{~ms} /$ phase pulse trains). Thus, this mechanism alone cannot explain the results obtained in this study.

Site of excitation. It is probable that the sites of excitation differ between animals with hair cells and peripheral processes and those without these elements near the electrodes. Shepherd et al. (2001) found differences in chronaxie between the shortterm and long-term deafened cochleae that were attributed to differences in the site of electrical excitation. In a cochlea with no hair cells or peripheral processes, the site of action potential initiation is probably at the SGN cell body or central process. However, in group I animals, initial depolarization could have occurred at the hair cell and/or peripheral process instead of the SGN body (van den Honert and Stypulkowski 1984). We hypothesize that the site of excitation in response to both pulsatile and sinusoidal stimulation was at the hair cell and/or peripheral process in group I animals and at the SGN cell body or central process in group II animals. Differences in membrane properties at the hair cell or peripheral process versus the SGN cell body or central process might explain why group I animals were more sensitive to one type of stimulus $(0.02 \mathrm{~ms} /$ phase pulses $)$, but group II animals were more sensitive to another $(100 \mathrm{~Hz}$ sinusoids, which have a phase duration of $5 \mathrm{~ms}$ ).

Neural membranes integrate charge over the phase duration (amount of time spent in the half cycle of the stimulus where the current is in one phase) until the threshold for depolarization is reached. In this study, the phase duration of the pulsatile stimulus was shorter than that of the sinusoidal stimulus. Parkins and Colombo (1987) showed that single neuron thresholds in deafened squirrel monkeys are primarily a function of pulse width and not of pulse shape or pulse rate. Furthermore, the strength-duration curves are sensitive to changes in the site of excitation, such as the length of the unmyelinated termination of the auditory neuron (Colombo and Parkins 1987). Because strength-duration curves are altered by the condition of the stimulated neurons, the stark differences in auditory neuron survival observed between group I and group II animals could have resulted in distinct strength-duration functions that intersected at a phase duration between $0.02 \mathrm{~ms} /$ phase (our pulsetrain stimulus) and $5 \mathrm{~ms} /$ phase (our sinusoidal stimulus). Although group I animals had lower thresholds with the pulsatile stimulus, if the magnitude of the slopes of the strength-duration function were greater in group II animals, this might explain the lower thresholds observed with the $100-\mathrm{Hz}$ sinusoidal stimulus. Changing from a relatively short phase duration pulse-train stimulus to a sinusoidal stimulus with a longer phase duration might have had a larger effect on thresholds in this group of animals.

Electrophonic effects. If electrophonic hearing occurred in group I animals, one would expect to find lower electrical psychophysical thresholds in these animals as single fiber electrophonic thresholds are lower than direct-membrane depolarization thresholds, resulting in an electrophonic "advantage" (Moxon 1971). Moreover, Moxon (1971) found that as sinusoidal frequency decreased (and phase duration increased), the difference between the electrophonic threshold and the direct-membrane depolarization threshold decreased. Thus, the magnitude of the electrophonic "advantage" might depend upon certain parameters of the electrical stimulus, including frequency and phase duration. 
The fact that the electrophonic "advantage" might depend on properties of the electrical stimulus might explain the observed threshold differences between group I and group II animals. It is possible that the stimulus parameters in this study were such that electrophonic hearing was present in response to $0.02 \mathrm{~ms} /$ phase pulse trains but absent in response to $100 \mathrm{~Hz}$ sinusoids. This scenario would be expected to result in an electrophonic "advantage" and lower thresholds in group I animals in response to pulsatile stimulation. However, if electrophonic hearing was absent in response to $100 \mathrm{~Hz}$ sinusoidal stimulation, other factors such as increased across-fiber synchrony in group II animals could have resulted in lower psychophysical thresholds in response to sinusoidal stimulation.

As van den Honert and Stypulkowski (1984) have suggested, electrophonic hearing is less likely to occur in animals with high acoustic thresholds than in those with good acoustic hearing. Interestingly, the three group I animals that showed threshold versus pulse rate functions similar to those of group II animals at site $1(348,361$, and 399) were among those with the highest acoustic thresholds at two or more of the tested frequencies. The number of cases is too small to draw definitive conclusions, but the data are consistent with the idea that electrophonic hearing played a role in the group I to group II differences.

Implications of the impedance data. We note that average impedances for group II animals were significantly higher than those for group I. This might have been due to greater tissue growth in the neomycin-treated ears as has been suggested in previous studies (Newbold et al. 2004). We did not see evidence of this in the histology of the current study, but that may have been missed due to the small number of neomycin-treated animals that underwent histological examination and possible disruption of tissue when the implant was extracted. Since we used a controlled current stimulator, higher impedances would not affect current levels. However, if the higher impedances reflected the presence of foreign tissue near the implant, this tissue could affect current delivery to the neurons, providing a possible fifth mechanism underlying the differences between groups I and II.

\section{Summary}

In summary, the preservation of acoustic hearing following cochlear implantation in group I animals probably affected two temporal processes involved in the perception of cochlear implant stimulation: (1) the integration of responses to pulses or sinusoids over the $200 \mathrm{~ms}$ stimulus duration and (2) the integration of current during each phase of the biphasic pulses or the sinusoidal stimuli. We found that preserving hearing affected the psychophysical perception of an electrical stimulus and the effect of hearing preservation on the perception of an electrical stimulus likely depended on the temporal properties (pulse rate, phase duration, etc.) of the electrical stimulus. Each of the mechanisms described above could potentially have played a role in the observed differences between group I and group II animals. Further experiments are needed to clarify the relative contributions of these various mechanisms.

\section{Clinical implications}

With advancing technology and the trend toward implanting more patients with residual hearing, it is plausible that future cochlear implant recipients might have hair cells in close proximity to the implant. Thus, it will be helpful to know whether or not implantation, electrical stimulation, and/or the long-term presence of the electrode array causes hair cell degeneration and loss of acoustic hearing over time. Our results suggest that hair cells, peripheral processes, and SGN cell bodies can survive cochlear implantation and electrical stimulation over a time period of 14 to 21 months in regions adjacent and apical to the electrode array. Furthermore, the ability to detect acoustic pure tones was also preserved over the same time period. These findings are encouraging as they extend the timeline of survival for hair cell preservation following cochlear implantation and suggest that preservation of the ability to detect acoustic stimuli as long as 21 months following cochlear implantation is achievable. This result is encouraging for clinical practice and for research that requires long-term stable conditions for analysis of implant function.

In addition, the data show that preservation of these cochlear structures influences the perception of an electrical stimulus. Our results suggest that the extent of hearing preservation during cochlear implantation might interact with the temporal features of the electrical stimulus, affecting the psychophysical response to cochlear implant stimulation. Based upon the findings of this study, future research might show that preserving hair cells adjacent to the electrode array also affects a variety of perceptual functions such as electrical pulse-train modulation detection, gap detection, and speech recognition that also depend on the encoding of temporal features of the stimuli. Furthermore, patients might respond differently to various temporal properties of the electrical stimulus, depending upon the condition of the cochlear structures surviving near the implant. 


\section{ACKNOWLEDGEMENTS}

This work was initiated and supported by NIH/NIDCD R01 DC007634 with additional support from the Alan and Berte Hirschfield Foundation, the R. Jamison and Betty Williams Professorship, the A. Alfred Taubman Medical Research Institute, and R01 DC004312, T32DC005356, P30 DC05188. We thank Lisa Beyer for her assistance with histology, and Karin Halsey and Dr. David Dolan for their work with the ensemble spontaneous activity recordings. We appreciate the comments of three anonymous reviewers and the editor and associate editor of JARO for their helpful comments on previous drafts of this manuscript.

\section{REFERENCES}

Berrettini S, Forli F, Passetti S (2008) Preservation of residual hearing following cochlear implantation: comparison between three surgical techniques. J Laryngol Otol 122:246-252

Cartee LA, van den Honert C, Finley CC, Miller RL (2000) Evaluation of a model of the cochlear neural membrane. I. Physiological measurement of membrane characteristics in response to intrameatal electrical stimulation. Hear Res 146:143-152

Cartee LA, Miller CA, van den Honert C (2006) Spiral ganglion cell site of excitation I: comparison of scala tympani and intrameatal electrode responses. Hear Res 215:10-21

Chatfield C, Collins AJ (1980) Introduction to multivariate analysis. Chapman and Hall, London, U.K.

Chikar JA, Colesa DJ, Swiderski DL, Polo AD, Raphael Y, Pfingst BE (2008) Over-expression of BDNF by adenovirus with concurrent electrical stimulation improves cochlear implant thresholds and survival of auditory neurons. Hear Res 245:24-34

Coco A, Epp SB, Fallon JB, Xu J, Millard RE, Shepherd RK (2007) Does cochlear implantation and electrical stimulation affect residual hair cells and spiral ganglion neurons? Hear Res 225:60-70

Colombo J, Parkins CW (1987) A model of electrical excitation of the mammalian auditory-nerve neuron. Hear Res 31:287-311

Davies E, Gladstone HB, Williams H, Hradek G, Shah SB, Schindler RA (1994) A model for long-term intracochlear administration of pharmacologic agents. Am J Otol 15:757-761

Dolan DF, Nuttall AL, Avinash G (1990) Asynchronous neural activity recorded from the round window. J Acoust Soc Am $87: 2621-2627$

DuckerT LG (1983) Morphological changes in the normal and neomycin-perfused guinea pig cochlea following chronic prosthetic implantation. Laryngoscope 93:841-855

Duckert LG, Miller JM (1982) Acute morphological changes in guinea pig cochlea following electrical stimulation. A preliminary scanning electron microscope study. Ann Otol Rhinol Laryngol 91:33-40

Eshraghi AA, Polak M, He J, Telischi FF, Balkany TJ, Van De Water TR (2005) Pattern of hearing loss in a rat model of cochlear implantation trauma. Otol Neurotol 26:442-447

Galvin JJ III, Fu Q-J (2005) Effects of stimulation rate, mode and level on modulation detection by cochlear implant users. J Assoc Res Otolaryngol 6:269-279

Gantz BJ, Turner CW (2003) Combining acoustic and electrical hearing. Laryngoscope 113:1726-1730

Green SH, Altschuler RA, Miller JM (2008) Cell death and cochlear protection. In: Schacht J, Popper AN, Fay RR (eds) Auditory trauma, protection and repair. Springer, New York, pp $275-320$
Gstoettner WK, Helbig S, Maier N, Kiefer J, Radeloff A, Adunka OF (2006) Ipsilateral electric acoustic stimulation of the auditory system: results of long-term hearing preservation. Audiol Neurootol 11(Suppl. 1):49-56

Haenggeli A, Zhang JS, Vischer MW, Pelizzone M, Rouiller EM (1998) Electrically evoked compound action potential (ECAP) of the cochlear nerve in response to pulsatile electrical stimulation of the cochlea in the rat: effects of stimulation at high rates. Audiology 37:353-371

Hu N, Abbas PJ, Miller CA, Robinson BK, Nourski KV, Jeng FC, Abkes BA, Nichols JM (2003) Auditory response to intracochlear electric stimuli following furosemide treatment. Hear Res 185:77-89

James C, Albegger K, Battmer R, Burdo S, Deggouj N, Deguine O, Dillier N, Gersdorff M, Laszig R, Lenarz T, Rodriguez MM, Mondain M, Offeciers E, Macias AR, Ramsden R, Sterkers O, Von Wallenberg E, Weber B, Fraysse B (2005) Preservation of residual hearing with cochlear implantation: how and why. Acta Otolaryngol 125:481-491

Kanzaki S, Stover T, Kawamoto K, Prieskorn DM, Altschuler RA, Miller JM, RAPHAEL Y (2002) Glial cell line-derived neurotrophic factor and chronic electrical stimulation prevent VIII cranial nerve degeneration following denervation. J Comp Neurol 454:350-360

Kiefer J, Pok M, Adunka O, Sturzebecher E, Baumgartner W, Schmidt M, Tillein J, Ye Q, Gstoettner W (2005) Combined electric and acoustic stimulation of the auditory system: results of a clinical study. Audiol Neurootol 10:134-144

KIM YH, RAPHAEL Y (2007) Cell division and maintenance of epithelial integrity in the deafened auditory epithelium. Cell Cycle 6(5):612-619

Le Prell CG, Kawamoto K, Raphael Y, Dolan DF (2006) Electromotile hearing: acoustic tones mask psychophysical response to high-frequency electrical stimulation of intact guinea pig cochleae. J Acoust Soc Am 120:3889-3900

Matsuoka AJ, Abbas PJ, Rubinstein JT, Miller CA (2000) The neuronal response to electrical constant-amplitude pulse train stimulation: additive Gaussian noise. Hear Res 149:129-137

McAnally KI, Clark GM, Syka J (1993) Hair cell mediated responses of the auditory nerve to sinusoidal electrical stimulation of the cochlea in the cat. Hear Res 67:55-68

Middebrooks JC (2004) Effects of cochlear-implant pulse rate and inter-channel timing on channel interactions and thresholds. J Acoust Soc Am 116:452-468

Middlebrooks JC, SNyder RL (2007) Auditory prosthesis with a penetrating nerve array. J Assoc Res Otolaryngol 8:258-279

Miller AL, Morris DJ, Pfingst BE (2000) Effects of time after deafening and implantation on guinea pig electrical detection thresholds. Hear Res 144:175-186

Miller CA, Abbas PJ, Robinson BK (2001) Response properties of the refractory auditory nerve fiber. J Assoc Res Otolaryngol 2:216-232

Miller CA, Abbas PJ, Robinson BK, Nourski KV, Zhang F, Jeng FC (2006) Electrical excitation of the acoustically sensitive auditory nerve: single-fiber responses to electric pulse trains. J Assoc Res Otolaryngol 7:195-210

Moxon EC (1971) Neural and mechanical responses to electric stimulation of the cat's inner ear. Doctoral dissertation, MIT, Cambridge, MA

Newbold C, Richardson R, Huang CQ, Milojevic D, Cowan R, SHEPHERD R (2004) An in vitro model for investigating impedance changes with cell growth and electrical stimulation: implications for cochlear implants. J Neural Eng 1:218-227

Ni D, Shepherd RK, Seldon HL, Xu SA, Clark GM, Millard RE (1992) Cochlear pathology following chronic electrical stimulation of the auditory nerve. I: normal hearing kittens. Hear Res 62:63-81 
Nuttall AL, Ren T (1995) Electromotile hearing: evidence from basilar membrane motion and otoacoustic emissions. Hear Res 92:170-177

Nuttall AL, Marques DM, Lahrence M (1977) Effects of perilymphatic perfusion with neomycin on the cochlear microphonic potential in the guinea pig. Acta Otolaryngol 83:393-400

Parkins CW, Colombo J (1987) Auditory-nerve single-neuron thresholds to electrical stimulation from scala tympani electrodes. Hear Res 31:267-285

Pfingst BE (1990) Changes over time in thresholds for electrical stimulation of the cochlea. Hear Res 50:225-236

Pfingst BE, Colesa DJ (2003) Some effects of electrode location on cochlear implant function. Assoc Res Otolaryngol Abs 26:59-60

Pfingst BE, Sutton D (1983) Relation of cochlear implant function to histopathology in monkeys. Ann N Y Acad Sci 405:224-239

Pfingst BE, Xu L, Thompson CS (2007) Effects of carrier pulse rate and stimulation site on modulation detection by subjects with cochlear implants. J Acoust Soc Am 121:2236-2246

Prado-Guitierrez P, Fewster LM, Heasman JM, McKay CM, Shepherd RK (2006) Effect of interphase gap and pulse duration on electrically evoked potentials is correlated with auditory nerve survival. Hear Res 215:47-55

Rice WR (1989) Analyzing tables of statistical tests. Evolution 43:223-225

Searchfield GD, Munoz DJ, Thorne PR (2004) Ensemble spontaneous activity in the guinea-pig cochlear nerve. Hear Res 192:23-35

SEwELL WF (1984) The relation between the endocochlear potential and spontaneous activity in auditory nerve fibres of the cat. J Physiol 347:685-696

SHEPHERD RK, JAVEL E (1997) Electrical stimulation of the auditory nerve. I. Correlation of physiological responses with cochlear status. Hear Res 108:112-144

Shepherd RK, HARdie NA, BAXI JH (2001) Electrical stimulation of the auditory nerve: single neuron strength-duration functions in deafened animals. Ann Biomed Eng 29:195-201

SpoENDLIN H (1984) Factors inducing retrograde degeneration of the cochlear nerve. Ann Otol Rhinol Laryngol Suppl 112:76-82

Stevens SS, Jones RC (1939) The mechanism of hearing by electrical stimulation. J Acoust Soc Am 10:261-269

Stollwerck Le, Goodrum-Clarke K, Linch C, Armstrong-Bednall G, NunN T, MARkoff L ET AL (2001) Speech processing strategy preferences among 55 European CLARION cochlear implant users. Scand Audiol Suppl 52:36-38
Su GL, Colesa DJ, Pfingst BE (2008) Effects of deafening and cochlear implantation procedures on postimplantation psychophysical electrical detection thresholds. Hear Res 241:64-72

Turner CW, Reiss LA, Gantz BJ (2008) Combined acoustic and electric hearing: preserving residual acoustic hearing. Hear Res 242:164-171

van den Honert C, STypulkowski PH (1984) Physiological properties of the electrically stimulated auditory nerve. II. Single fiber recordings. Hear Res 14:225-243

Vischer M, Haenggeli A, Zhang J, Pelizzone M, Hausler R, Rouiller EM (1997) Effect of high-frequency electrical stimulation of the auditory nerve in an animal model of cochlear implants. Am J Otol 18:S27-S29

von Ilberg C, Kiefer J, Tillein J, Pfenningdorff T, Hartmann R, StURZEBecher E, KuINKE R (1999) Electric-acoustic stimulation of the auditory system. New technology for severe hearing loss. ORL J Otorhinolaryngol Relat Spec 61:334-340

Walsh SM, Leake-Jones PA, Vurek LS, Merzenich MM (1981) Chronic electrical stimulation with intracochlear electrodes: electrophysiological results. Ann Otol Rhinol Laryngol Suppl 90:27-29

Webster M, Webster DB (1981) Spiral ganglion neuron loss following organ of Corti loss: a quantitative study. Brain Res 212:17-30

WILSON BS (1997) The future of cochlear implants. Br J Audiol 31:205-225

Wilson BS, Dorman MF (2008) Cochlear implants: a remarkable past and a brilliant future. Hear Res 242:3-21

Wilson BS, Finley CC, Lawson DT, Zerbi M (1997) Temporal representations with cochlear implants. Am J Otol 18:S30S34

Xu J, Shepherd RK, Millard RE, Clark GM (1997) Chronic electrical stimulation of the auditory nerve at high stimulus rates: a physiological and histopathological study. Hear Res 105:1-29

Xu L, Zwolan TA, Thompson CS, Pfingst BE (2005) Efficacy of a cochlear implant simultaneous analog stimulation strategy coupled with a monopolar electrode configuration. Ann Otol Rhinol Laryngol 114:886-893

Yagi M, Kanzaki S, Kawamoto K, Shin B, Shah PP, Magal E, Sheng J, RAPHAEL Y (2000) Spiral ganglion neurons are protected from degeneration by GDNF gene therapy. J Assoc Res Otolaryngol $1: 315-325$

Zwolan T, Kileny PR, Smith S, Mills D, Koch D, Osberger MJ (2001) Adult cochlear implant patient performance with evolving electrode technology. Otol Neurotol 22:844-849 